\title{
Energy Metabolism of Rabbit Retina as Related to Function: High Cost of $\mathrm{Na}^{+}$Transport
}

\author{
Adelbert Ames III, Ying-ying Li, ${ }^{a}$ Eliot C. Heher, ${ }^{b}$ and Catherine Rising Kimble ${ }^{c}$ \\ Neurosurgical Service, Massachusetts General Hospital, Boston, Massachusetts 02114
}

\begin{abstract}
Experiments designed to examine the energy requirements of neurophysiological function were performed on isolated rabbit retina. Function was altered by photic stimulation or by function-specific drugs, and the response of energy metabolism was assessed by simultaneous measurements of $\mathrm{O}_{2}$ consumption and lactate production. In other experiments, the supply of $\mathrm{O}_{2}$ or glucose was reduced and the effect on energy metabolism and electrophysiological function was observed.
\end{abstract}

Energy requirements under control conditions in darkness were high, with $\mathrm{O}_{2}$ consumption (per gm dry wt) at $11.3 \mu \mathrm{mol}$ min $^{-1}$, with lactate production at $14.8 \mu \mathrm{mol} \mathrm{min}$ me $^{-1}$, and with the derived value for glucose consumption at $9.3 \mu \mathrm{mol}$ min $^{-1}$ and for high-energy phosphate $(\sim P)$ generation at 82.6 emol min $^{-1}$.

Energy reserves were small. Removing glucose abolished the b-wave of the electroretinogram (ERG) with a $t_{1 / 2}$ of 1 min, but did not immediately affect $\mathrm{O}_{2}$ consumption or the PIII of the ERG. Removing $\mathrm{O}_{2}$ caused increases of up to 2.7fold in glycolysis (Pasteur effect) and caused both PIII and b-wave to fail, with a $t_{1 / 2}$ of about $5 \mathrm{~min}$.

Neurotransmission through the inner retina was supported almost entirely by glycolysis, as evidenced by large increases in lactate production in response to flashing light and decreases in response to transmitter blockers (2.3-fold overall change), with no change in $\mathrm{O}_{2}$ consumption. Phototransduction, on the other hand, was normally supported by oxidative metabolism. The dark current accounted for $41 \%$ of the retina's $\mathrm{O}_{2}$ consumption. With $\mathrm{O}_{2}$ reduced, the dark current was partially supported by glycolysis, which accounts (at least in part) for the large Pasteur effect.

$\mathrm{Na}^{+}$transport by NaK ATPase accounted for about half of all energy used, as evidenced by the response to strophanthidin, that is, for $49 \%$ of the oxidative energy and $58 \%$ of the glycolytic energy. The $t_{1 / 2}$ for the turnover of intracellular $\mathrm{Na}^{+}$was calculated from these data to be less than $1 \mathrm{~min}$.

\footnotetext{
Received May 21, 1991; revised Oct. 8, 1991; accepted Oct. 10, 1991.

This work was supported by NIH Grant NS 25753. We thank Caleb Warner for assistance in the design and fabrication of the apparatus, and Dr. Mark Barad for machining some of the apparatus and for helping to solve early problems encountered in its use. We thank Dr. John Peterson for devising the electrical circuits for recording from the $\mathrm{O}_{2}$ electrodes.

Correspondence should be addressed to Dr. Adelbert Ames III, 401 Warren Building, Massachusetts General Hospital, Boston, MA 02114.

Present address: Department of Behavioral Neuroscience, University of Pittsburgh, Pittsburgh, PA 15260.

${ }^{\circ}$ Present address: Department of Medicine, The Johns Hopkins Hospital, Baltimore, MD 21218.

c Present address: McLean Hospital, Belmont, MA 02178.

Copyright (C) 1992 Society for Neuroscience $0270-6474 / 92 / 120840-14 \$ 05.00 / 0$
}

Changes in temperature caused changes in the amplitude of light-evoked electrical responses of $6.5 \%$ per degree and caused changes in both $\mathrm{O}_{2}$ consumption and glycolysis of $6.8 \%$ per degree $\left(Q_{10}=1.9\right)$.

A surprisingly large fraction of oxidative energy, corresponding to about $\mathbf{4 0} \%$ of the total energy generated, could not be assigned to phototransduction, to neurotransmission, to $\mathrm{Na}^{+}$transport for other purposes, or to vegetative metabolism. We cannot account for its usage, but it may be related to the (previously reported) rapid turnover of the $\gamma$-phosphate of retinal GTP, the function of which also remains unknown.

We conclude that most of the high-energy metabolism of retina is required to support function. Some of the most energy-demanding functions remain to be identified.

Nervous tissue is distinctive in requiring a high level of energy metabolism. However, relatively few studies have been performed in which energy metabolism has been measured and related to the processes for which it is being used. This is attributable in large part to the experimental difficulties inherent in measuring the rate of energy metabolism as distinguished from the state of energy metabolism. The state of energy metabolism, or the adequacy of supply relative to demand, can be determined relatively easily by measuring the levels of $\mathrm{CrP}$, ATP, ADP, and $P_{i}$. Measuring the rate is much more difficult.

The rate of energy production can be calculated from the rate of $\mathrm{O}_{2}$ consumption and lactate production, but in vivo this requires measurements of arteriovenous differences and of blood flow, which are difficult to obtain, particularly for specific regions of the CNS. The technique, introduced by Sokoloff, of using the rate of 2-deoxyglucose accumulation as a measure of the cncrgy metabolism has been remarkably valuable, but it depends on conditions that may not remain constant or may not always be met-the components of the "lumped constant," a negligibly low level of phosphatase activity and a negligibly low (or at least constant) level of glycolysis relative to oxidative metabolism. A novel approach to the measurement of energy metabolism with considerable potential is the measurement of the rate of high-energy phosphate $(\sim \mathrm{P})$ hydrolysis using $\mathrm{H}_{2}{ }^{18} \mathrm{O}$, but this is analytically difficult and has been relatively little employed (see Discussion). Neither of the last two methods cited permits a distinction to be made between energy derived from glycolysis and from oxidative metabolism.

Because of the difficulty of these measurements, many important questions remain unanswered. Which of the processes involved in keeping resting neurons in an excitable state are the principal energy consumers? Which require the greatest increases in energy when the cells are activated? Can function-related 
energy demands ever exceed the normal supply of energy to an extent that limits function and threatens homeostasis? Which processes depend on oxidative metabolism and which depend on glycolysis, and to what extent is there an obligatory linkage between the type of energy generation and the process for which it is used?

We describe here experiments relating energy metabolism to function that were performed on isolated rabbit retina and that used a recently developed technique providing on-line measurements of both $\mathrm{O}_{2}$ consumption and lactate production. Retina offered a number of advantages for this study: it contains cells that are highly specialized to be sensitive transducers of light, and it contains a much studied neural network that processes the output of these photoreceptors. It can be maintained in markedly different states of physiological activity by subjecting it to different types of photic stimuli. It can be studied in vitro in a nearly physiological state, which makes it possible not only to measure $\mathrm{O}_{2}$ consumption and lactate production more accurately, but also to alter energy metabolism directly by varying $\mathrm{O}_{2}$ and glucose, and to alter energy-requiring functions by the introduction (and removal) of defined concentrations of pharmacologic agents. Electrical evidence of the changes in function caused by light or by the pharmacological agents can be obtained from the electroretinogram (ERG). Another advantage of retina is the amount of information that has been accumulated about its energy metabolism over many years (e.g., Craig and Beecher, 1943; Lowry et al., 1956; Noell, 1958; Graymore, 1959; Sickel, 1972; Niemeyer, 1975; Winkler, 1981; Steinberg, 1987; Linsenmeier, 1990).

Though retina offers these advantages for studying relationships between function and energy metabolism, it should be recognized that retina is highly specialized, particularly with respect to its capacity for phototransduction, which requires an energy-demanding light-sensitive current, and with respect to its blood supply. All retinas are avascular in their outer portion. Rabbit retina (as distinct from many others including primate) is avascular throughout, and it receives nearly all its nutrition by diffusion from the choroid. The difference in vasculature between rabbit and primate retina is reflected in the distribution of enzymes related to energy production, rabbit retina having almost exclusively glycolytic enzymes in its inner layers (Lowry et al., 1956). Because of these differences, any comparisons between the energy metabolism of retina and other portions of the CNS, or between rabbit retina and retinas of other species, must be made with caution.

It would be desirable to characterize the energy requirements of particular physiological functions and particular cell types. The process of phototransduction is so different from other retinal functions (with respect to its preferred stimulus, its response to pharmacologic agents, and its electrical manifestations) that it is possible to estimate its energy requirements on the basis of measurements made on the entire retina. Some inferences can also be drawn about the energy requirements of neurotransmission through the retina. More detailed allocations of energy usage will depend on further improvements in techniques.

\section{Materials and Methods}

Tissue preparation. New Zealand White rabbits weighing about $3 \mathrm{~kg}$ were dark adapted for $1 \mathrm{hr}$, sedated with sodium pentobarbital $(15 \mathrm{mg} /$ $\mathrm{kg}$ ), and brought to a surgical anesthetic level with ether by mask. The eyes were removed and the retinas were isolated under dim red light.

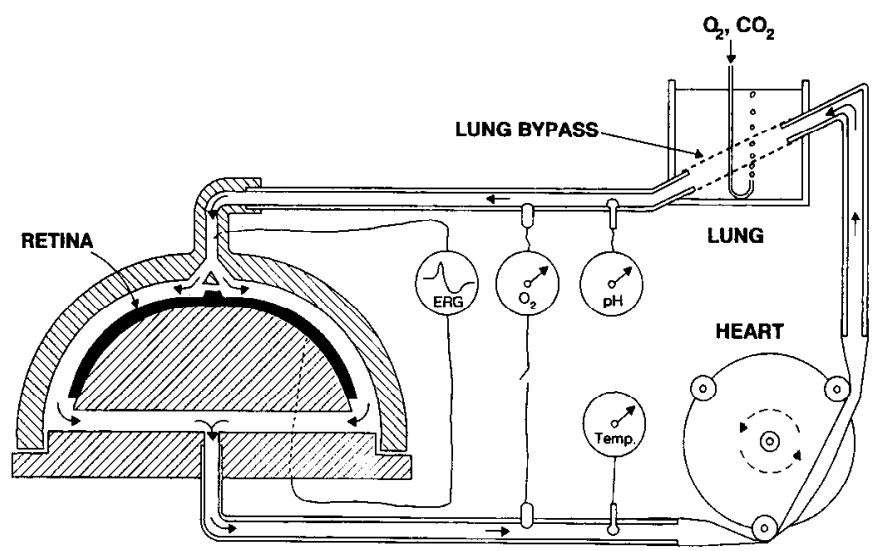

Figure 1. Schematic drawing of heart-lung apparatus. Radial arrangement of channels delivering fluid to, and recovering fluid from, the retina ensured even flow over its surface. Broken lines show a connector that could be rapidly inserted between inlet and outlet of lung to prevent exchange between the medium and the gas phase when the apparatus was used in the lung-bypass mode. Electrical switch depicted between the $\mathrm{O}_{2}$ electrodes indicates there was a choice of recording the $\mathrm{O}_{2}$ concentration of medium returning to the retina, or recording the difference in the $\mathrm{O}_{2}$ concentrations of the medium before and after it had superfused the retina. See text for further description.

The animals were killed while still anesthetized. The retinas were maintained in darkness in a medium that simulated cerebrospinal fluid with respect to electrolytes and 38 organic constituents. A detailed account of the procedures used to isolate the retinas and of the composition of the medium has been presented (Ames and Nesbett, 1981). The medium for some of the experiments was purchased from Sigma (St. Louis, MO) as Ames Medium. The isolation and incubation of the retina were performed in a warm room maintained at $37^{\circ} \mathrm{C}$.

Immediately after its isolation, the retina was placed in a miniature "heart-lung" apparatus, shown diagrammatically in Figure 1. The retina was mounted with its vitreous surface down on a hemispherical mandrel that was enclosed in a hemispherical chamber so that the tissue was uniformly superfused by a $1-\mathrm{mm}$-deep layer of medium. The medium was circulated by a peristaltic pump (the "heart") that moved the medium in a circular system over the retina, through the pump, through a chamber in which it was equilibrated with the gas phase (the "lung"), and then over the retina again. The $\mathrm{CO}_{2}$ in the gas phase was always $5 \%$; the $\mathrm{O}_{2}$ was varied from $0 \%$ to $95 \%$, with the balance being $\mathrm{N}_{2}$.

Metabolic measurements. As shown in Figure 1, the apparatus contained two $\mathrm{O}_{2}$ electrodes (Clark Oxygen Probe, Yellow Springs Instrument Co., Yellow Springs, Ohio) to measure the $\mathrm{O}_{2}$ concentration, and a glass electrode to measure the $\mathrm{pH}$ of the medium. The outputs of these electrodes were conventionally amplified and displayed with a highspeed ink recorder (Gould). An electronic thermometer was used to record the temperature to within $0.1^{\circ} \mathrm{C}$ whenever a metabolic measurement was made.

The apparatus was used in two modes for measuring $\mathrm{O}_{2}$ consumption. In one mode, the "lung" was temporarily bypassed so that there was a continuing fall in the $\mathrm{O}_{2}$ in the small volume of recirculating fluid (see Figs. $7 A, 9 A$ ). The reduction observed in $1 \mathrm{~min}$, multiplied by the volume ( $2.3 \mathrm{ml})$, gave the rate of $\mathrm{O}_{2}$ consumption. For this measurement only the $\mathrm{O}_{2}$ electrode between the lung and the retina was used. In the other mode, the gas exchange in the lung was maintained and the difference in the outputs of two $\mathrm{O}_{2}$ electrodes (one sampling the medium just before and the other just after it had superfused the retina) was measured. This "arteriovenous" difference, multiplied by the rate of medium flow, gave the rate of $\mathrm{O}_{2}$ consumption (see Figs. $7 B, 9 B$ ). This method of recording was used to obtain the time course, as well as the amount, of a change in $\mathrm{O}_{2}$ consumption. The results obtained by the two methods agreed well, but the lung bypass method was somewhat more reproducible and was used for most of the recordings presented here.

Lactate production was calculated from the rate of fall of the $\mathrm{pH}$ of the medium when the apparatus was in the lung-bypass mode. The fall in $\mathrm{pH}$ was attributed to the generation of lactic acid from glycolysis and to the generation of $\mathrm{CO}_{2}$ from glucose oxidation, and since the latter 
was known from the rate of $\mathrm{O}_{2}$ consumption, the rate of lactic acid formation could be calculated.

A more detailed description of the measurements of $\mathrm{O}_{2}$ consumption and lactate production is presented in the Appendix, together with the equations used in the calculations.

Photic stimuli and electrophysiological recordings. Photic stimulation was provided by fluorescent lamps with a phosphor exhibiting rapid $(20 \mu \mathrm{sec})$ rise and fall times. Stimulus intensity was varied by rheostat control of the current to the lamps and by neutral density filters. As shown in Figure 1, platinum electrodes mounted within the apparatus on either side of the retina were used to record the electroretinogram (ERG).

Three types of photic stimulation were most frequently used: (1) a 10 msec flash of an intensity eliciting a maximum vitreous-positive response (b-wave), (2) an 800 or $1000 \mathrm{msec}$ flash of an intensity eliciting a near-maximum vitreous-negative response (PIII), and (3) a steady light eliciting a maximum PIII response and lasting several minutes, used to assess the metabolic effects of blocking the dark current. In a previous study using the same light source (Ames et al., 1986), we had characterized the stimuli in terms of photoisomerizations per rod outer segment per second $\left(\mathrm{Rh}^{*} \sec ^{-1}\right)$, and we had determined the stimuli that elicited a maximum b-wave (1-2 $\left.\mathrm{Rh}^{*} \mathrm{sec}^{-1}\right)$ and maximum PIII (500 $\left.\mathrm{Rh}^{*} \mathrm{sec}^{-1}\right)$. Since the retinas in the present study were under similar incubating conditions, the photic stimuli used for the b-wave and PIII are assumed to be similar. The optical characteristics of the heart-lung apparatus made a more direct measurement impractical. Except where otherwise indicated, the measurements of energy metabolism were performed in darkness.

In the absence of pigment epithelium (as in the present experiments), photic stimuli elicit a vitreous-negative transretinal response due to interruption of the dark current of the photoreceptors and a nearly simultaneous vitreous-positive response due to activation of ON-bipolar cells (b-wave and d.c. component). Though the former predominates with high-intensity stimuli and the latter with low-intensity stimuli, the ERG represents the net effects of responses of opposite sign and is interpretable only qualitatively. The b-wave and d.c. component (cf. Steinberg, 1969) are understood to represent a net effect, but the designation "PIII" is conventionally applicd to the photorcceptor responsc only, as measured in the presence of a synaptic blocker such as aspartate. We therefore have used the term in quotes when referring to the vitreousnegative response elicited by high-intensity stimuli in the absence of a synaptic blocker in the present experiments.

The responses of photoreceptors and bipolar cells recorded by ERG have been shown to depend in large part on ion movements through Müller cells. Therefore, while it seems likely that the changes in the ERG during anoxia and hypoglycemia reflect the effects of energy deprivation in the photoreceptors and bipolar cells (and we have interpreted them in this way), it is also possible that some changes in the ERG reflect the effects of energy deprivation in the Müller cells.

Modifications of the medium. In experiments to examine the effects of removing glucose, medium containing only the inorganic electrolytes and equilibrated with the control gas mixture $\left(5 \% \mathrm{CO}_{2}, 40 \% \mathrm{O}_{2}, 55 \%\right.$ $\mathrm{N}_{2}$ ) was delivered to the outlet of the lung so that the retina was superfused with substrate-free medium within $7 \mathrm{sec}$. In experiments on the effects of removing $\mathrm{O}_{2}$, control medium equilibrated with $5 \% \mathrm{CO}_{2}$ and $95 \% \mathrm{~N}_{2}$ was introduced in the same way. In some experiments, a combination of three glutamate analogs was added to the medium to inhibit transmission: APB (DL-2-amino-4-phosphonobutyric acid), an inhibitory agonist at ON-bipolars; APV (DL-2-amino-5-phosphonovaleric acid), an antagonist at NMDA receptors; and CNQX (6-cyano-7nitroquinoxaline-2,3-dione), an antagonist at kainate receptors. IBMX (3-isobutyl-1-methylxanthine) was used as a phosphodiesterase inhibitor to modify phototransduction. Strophanthidin was used to inhibit NaK ATPase. Strophanthidin, APB, and APV were obtained from Sigma (St. Louis, MO). CNQX was obtained from Cambridge Research Biochemicals (Wilmington, DE), and IBMX was obtained from Aldrich (Milwaukee, MI). The various reagents were prepared as more concentrated stock solutions in medium and added to the circulating medium in the lung.

Experimental variability and collation of data. The electrical responses to photic stimulation and the rates of $\mathrm{O}_{2}$ consumption and lactate production remained quite constant under control conditions for many hours. Replicate measurements were very reproducible. In 43 consecutive experiments in which three or more consecutive measurements were obtained under control conditions, the standard deviations ex- pressed as percentage of the mean were $2.1 \pm 0.3\left( \pm\right.$ SE) for $\mathrm{O}_{2}$ consumption and $4.4 \pm 0.4$ for lactate production. Most of the variability between experiments was attributable to differences in the size of the retinas. Therefore, retinas have usually been used as their own controls, and the results have been expressed and averaged, as percentage change from the control state. Comparisons between test and control conditions were made on the basis of averaged values for two or more measurements under each condition.

The responses to most of the experimental variables examined were fully reversible, so a number of variables were tested on each retina in experiments that usually lasted 6-8 hr.

Selection of control conditions. A series of preliminary experiments was performed to identify an $\mathrm{O}_{2}$ concentration and flow rate that would simulate conditions in vivo. Because of the low solubility of $\mathrm{O}_{2}$ in medium and the high $\mathrm{O}_{2}$ consumption of the retina, there is a layer of medium next to the tissue that is relatively low in $\mathrm{O}_{2}$, even when flow rates are quite fast. Therefore, in order to maintain an adequate level of $\mathrm{O}_{2}$ in the fluid in immediate contact with the cells, it is necessary to increase the $\mathrm{O}_{2}$ concentration in the bulk medium to levels considerably higher than those found in extracellular fluid in vivo. At the same time, it is undesirable to have the $\mathrm{O}_{2}$ at the site of the cells much higher than normal because of the possibility of toxicity (cf. Noell, 1958; Lucas, 1962). We used the response of the retina itself as an indicator of an appropriate delivery of $\mathrm{O}_{2}$, using the amplitudes of the b-wave and "PIII" to assess functional status and using the ratio of lactate production to $\mathrm{O}_{2}$ consumption as a sensitive indicator of metabolic status. In a similar study on perfused cat eye, Niemeyer (1975) examined the effect on the ERG of varying $p \mathrm{O}_{2}$ and perfusion rate.

As shown in the lower portion of Figure 2, with a flow rate of $2.3 \mathrm{ml}$ $\mathrm{min}^{-1}$, the ratio of lactate production to $\mathrm{O}_{2}$ consumption increased only slightly as the concentration of $\mathrm{O}_{2}$ (i.e., the $\mathrm{O}_{2}$ with which the bulk medium had been equilibrated) was reduced from $95 \%$ to $40 \%$, but at $20 \%$ and below, there was a marked increase in the ratio. With the flow increased to $4.6 \mathrm{ml} \mathrm{min}{ }^{-1}$, the ratios were a little lower at comparable $\mathrm{O}_{2}$ concentrations, and the concentration had to be reduced further before there was a marked increase in the ratio. As shown in the upper portion of Figure 2, electrophysiological function, assessed at the lower flow rate of $2.3 \mathrm{ml} \mathrm{min}-1$, showed no impairment when the $\mathrm{O}_{2}$ was reduced from $95 \%$ to $40 \%$ and was reduced by only $10 \%$ with $20 \% \mathrm{O}_{2}$. In vivo changes in retinal function become apparent before the $\mathrm{O}_{2}$ concentration has been reduced very far below its normal level. Steinberg (1987) and Linsenmeier (1990) report changes, with small reductions of $p \mathrm{O}_{2}$, in the standing potential and light-evoked response of cat retina, and Steinberg (1987) cites studies showing early changes in human dark adaptation. We therefore interpreted the data in Figure 2 to indicate that $40 \% \mathrm{O}_{2}$ with a flow rate of $4.6 \mathrm{ml} \mathrm{min}-1$ reproduced fairly closely the in vivo situation, and these were the conditions used for most of the experiments reported here. [The observation that increasing the $\mathrm{O}_{2}$ above $40 \%$ caused an increase in its consumption (see Fig. 4) raised a question as to whether $40 \%$ was adequate. However, in studies in vivo there was no evidence of a plateau in consumption when choroidal $p \mathrm{O}_{2}$ in the cat was progressively increascd up to its normal level (Linsenmeier, 1990), and when the $\mathrm{O}_{2}$ in the inhaled gas was increased from $20 \%$ to $100 \%$ there was an increase in the $\mathrm{O}_{2}$ consumption of pig retina (Pournaras et al., 1989). These findings both suggest that unphysiologically high levels of $\mathrm{O}_{2}$ can lead to abnormally high levels of consumption.]

Response to changes in temperature. A preliminary series of experiments was also undertaken to determine the effect of temperature on the energy metabolism. For these, the entire apparatus was immersed in a water bath that permitted the temperature to be adjusted over a $15^{\circ} \mathrm{C}$ range and maintained to within $\pm 0.2^{\circ} \mathrm{C}$. These experiments were conducted with $95 \% \mathrm{O}_{2}$ and a flow rate of $9 \mathrm{ml} \mathrm{min}^{-1}$ in order to avoid the possibility of $\mathrm{O}_{2}$ becoming a limiting factor at the higher temperatures. In the representative experiment shown in Figure 3, the initial observation was made at $35.3^{\circ} \mathrm{C}$, the temperature was reduced in steps to $28.7^{\circ} \mathrm{C}$, increased in steps to $38.3^{\circ} \mathrm{C}$, and then reduced in steps to $35.1{ }^{\circ} \mathrm{C}$. There was no evidence of hysteresis. As shown on the left, the amplitude of the b-wave increased $6.5 \%$ per degree over the range studied. $\mathrm{O}_{2}$ consumption and lactate production showed a similar response, each increasing $6.8 \%$ per degree, corresponding to a $Q_{10}$ of 1.93 . These data are quite consistent with previous studies of the effects of temperature on retinal function (Baylor et al., 1982) and on the energy metabolism of brain (e.g., Field et al., 1944; Michenfelder and Theye, 1968; Hagerdal et al., 1975; McCulloch et al., 1982).

The remainder of the experiments reported here were performed with- 

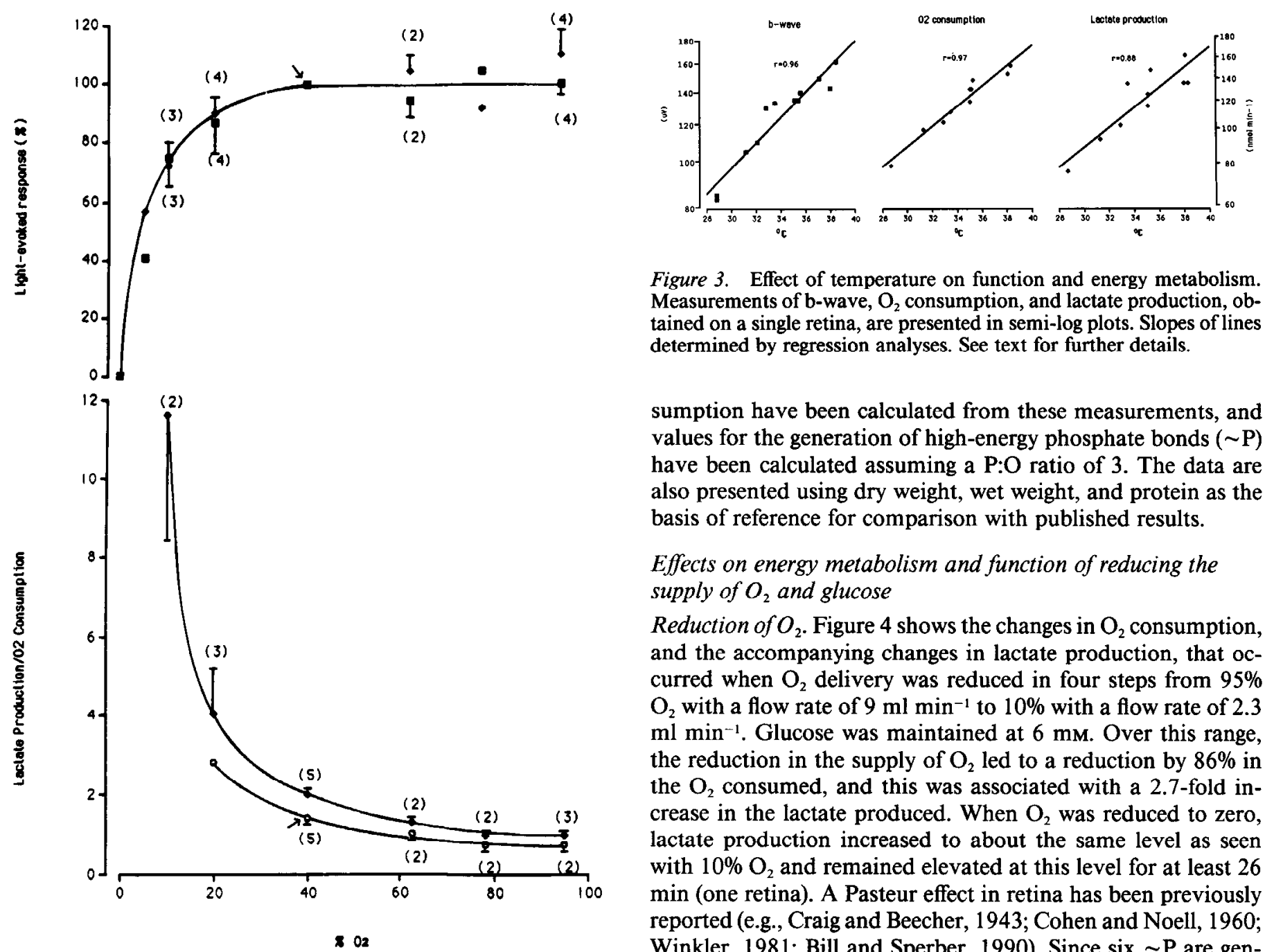

Figure 3. Effect of temperature on function and energy metabolism. Measurements of b-wave, $\mathrm{O}_{2}$ consumption, and lactate production, obtained on a single retina, are presented in semi-log plots. Slopes of lines determined by regression analyses. See text for further details.

sumption have been calculated from these measurements, and values for the generation of high-energy phosphate bonds $(\sim \mathrm{P})$ have been calculated assuming a $\mathrm{P}: \mathrm{O}$ ratio of 3 . The data are also presented using dry weight, wet weight, and protein as the basis of reference for comparison with published results.

\section{Effects on energy metabolism and function of reducing the supply of $\mathrm{O}_{2}$ and glucose}

Reduction of $\mathrm{O}_{2}$. Figure 4 shows the changes in $\mathrm{O}_{2}$ consumption, and the accompanying changes in lactate production, that occurred when $\mathrm{O}_{2}$ delivery was reduced in four steps from $95 \%$ $\mathrm{O}_{2}$ with a flow rate of $9 \mathrm{ml} \mathrm{min}-1$ to $10 \%$ with a flow rate of 2.3

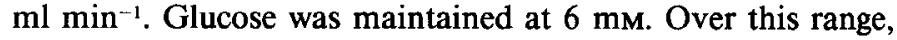
the reduction in the supply of $\mathrm{O}_{2}$ led to a reduction by $86 \%$ in the $\mathrm{O}_{2}$ consumed, and this was associated with a 2.7 -fold increase in the lactate produced. When $\mathrm{O}_{2}$ was reduced to zero, lactate production increased to about the same level as secn with $10 \% \mathrm{O}_{2}$ and remained elevated at this level for at least 26 min (one retina). A Pasteur effect in retina has been previously reported (e.g., Craig and Beecher, 1943; Cohen and Noell, 1960; Winkler, 1981; Bill and Sperber, 1990). Since six $\sim P$ are generated for each molecule of $\mathrm{O}_{2}$ consumed, but only one $\sim \mathbf{P}$ for each molecule of lactate produced, it is evident from these data that the increase in glycolysis in response to hypoxia failed to compensate for the energy lost from the reduction in oxidative metabolism. The three successive reductions in $\mathrm{O}_{2}$ delivery reduced the generation of $\sim \mathrm{P}$ to $78 \%, 54 \%$, and $40 \%$ of its $\max -$ imum level.

Function, as assessed by the amplitude of "PIII" and the b-wave, began to fail with $20 \% \mathrm{O}_{2}$ and a flow rate of $2.3 \mathrm{ml}$ $\min ^{-1}$; it was significantly reduced $(p<0.05)$ to about $73 \%$ of control levels with $10 \% \mathrm{O}_{2}$, and it was almost unrecordable with $0 \% \mathrm{O}_{2}$ (Fig. 2). In order to determine the time coursc of the loss of function, we subjected retinas to anoxia while monitoring electrical responses to light flashes delivered every $10 \mathrm{sec}$. When the control medium was replaced with medium that had been equilibrated with $95 \% \mathrm{~N}_{2}$ and $5 \% \mathrm{CO}_{2}$, the $\mathrm{O}_{2}$ electrodes adjacent to the retina showed that the $\mathrm{O}_{2}$ in the medium perfusing the tissue was reduced to $3 \%$ after $1 \mathrm{~min}$ and to $0.4 \%$ within 3 min. As shown in Figure 5, both the "PIII" and b-wave began to fail in about $1 \mathrm{~min}$ and were reduced to one-half of their control amplitudes in about $5 \mathrm{~min}$. Noell (1958) reported a similar, but somewhat more rapid response of the a-wave and b-wave to asphyxia in vivo. The "PIII" recovered from the 8 min period of anoxia more promptly than the b-wave. [The increased amplitude of "PIII" following the anoxia probably reflects, at least in part, a continued reduction in the amplitude 


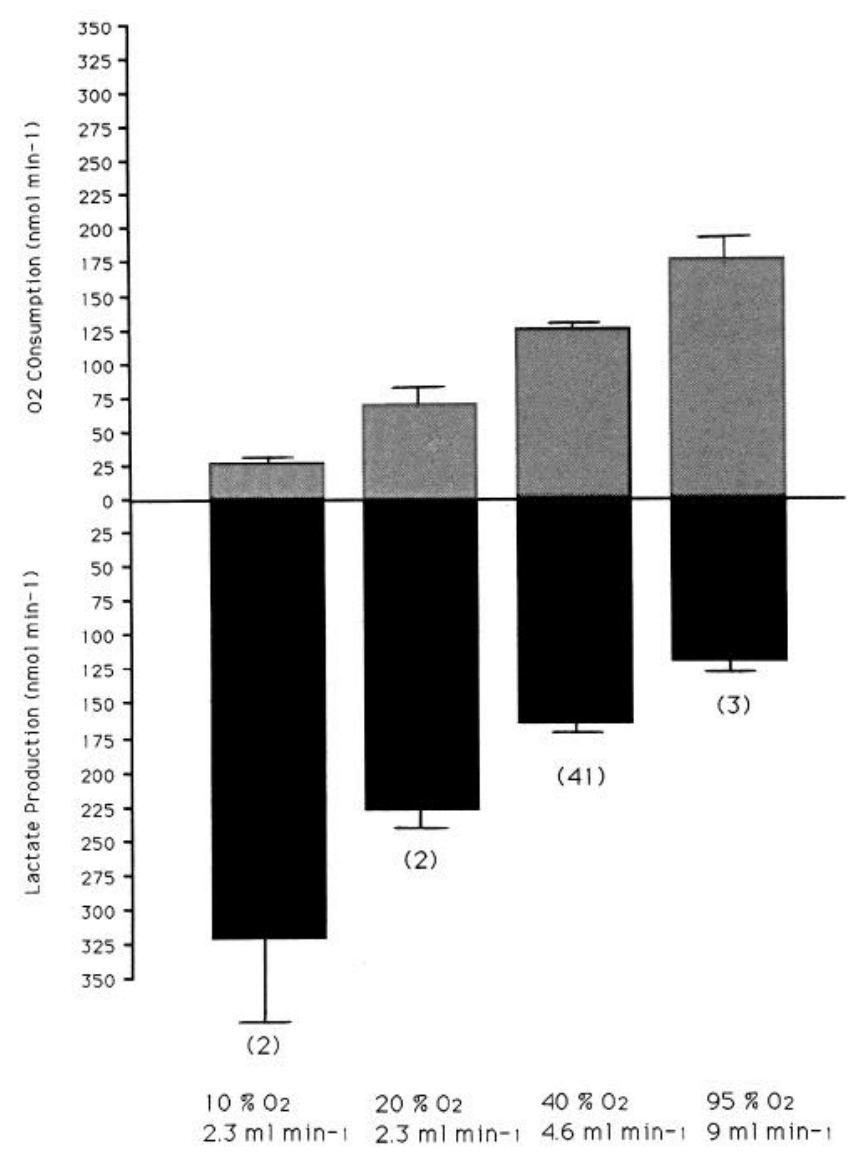

Figure 4. Pasteur effect. Measurements of $\mathrm{O}_{2}$ consumption and of lactate production were obtained on retinas being superfused at three rates with medium containing four concentrations of $\mathrm{O}_{2}$, as indicated below. Changes in $\mathrm{O}_{2}$ consumption and lactate production between successive bars are significant $(p<0.005)$, except between $20 \%$ and $10 \% \mathrm{O}_{2}$, where $n$ values were small.

of the potential(s) responsible for the b-wave and d.c. component; see Materials and Methods.]

Removal of glucose. Removing glucose (and all other organic substrates) from the medium caused lactate production to fall promptly to immeasurable levels, but it had surprisingly little effect on $\mathrm{O}_{2}$ consumption, due presumably to a shift to endogenous substrates (e.g., Norberg and Siesjo, 1976). In one representative experiment, $\mathrm{O}_{2}$ consumption had fallen by only $8 \%$ after $9 \mathrm{~min}$ without glucose and by $25 \%$ after $25 \mathrm{~min}$. The response of "PIII" and of the b-wave to a short period of glucose
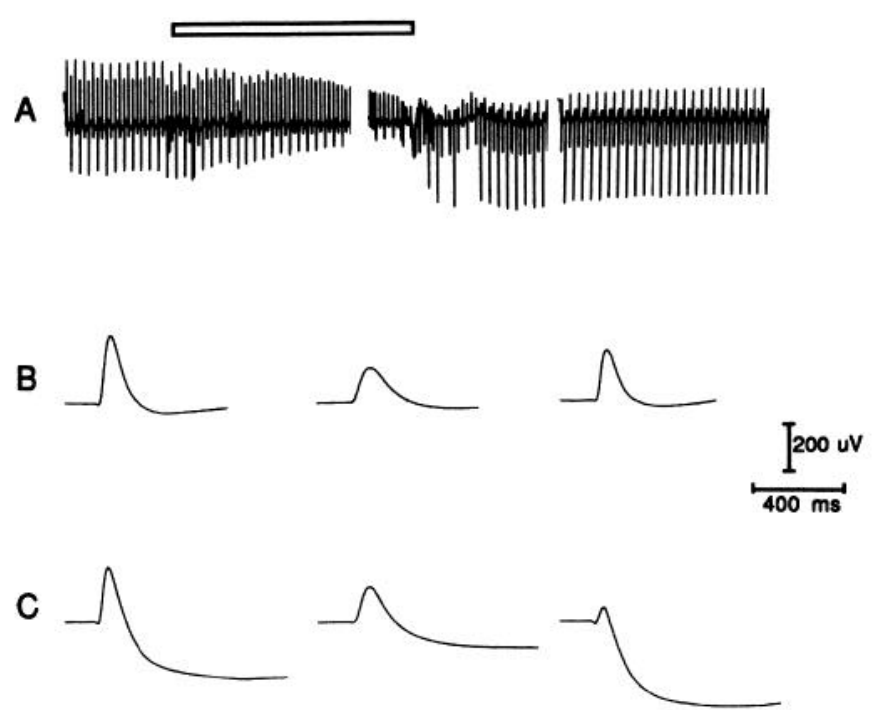

Figure 5. Effect of $\mathrm{O}_{2}$ deprivation on electrophysiological function. $A$, Response to a flash that was delivered every $10 \mathrm{sec}$ and that alternated between dim and bright was used to show time course of changes in b-wave (upward deflections) and "PIII" (downward deflections) during and following an $8 \mathrm{~min}$ period of anoxia (indicated by bar above). The recording was interrupted, near the end of the deprivation and during the recovery, to obtain the traces shown below. $B$ and $C$, Recordings at higher chart speed obtained during the course of the same deprivation show b-wave $(B)$ and "PIII" $(C)$ under control conditions (left), after 7 min of anoxia (center), and after $20 \mathrm{~min}$ of resupply (right). Voltage calibration applies to $A-C$; time calibration applies only to $B$ and $C$.

deprivation is shown in Figure 6. In the recording shown in Figure $6 A$, the monitoring flash was delivered every $5 \mathrm{sec}$ and maintained at the intensity that had elicited a maximum b-wave. Replacement of control medium by substrate-free medium was followed after only $30 \mathrm{sec}$ by a reduction of the b-wave, which was half gone by $55 \mathrm{sec}$ and had virtually disappeared by 115 sec. Recovery was somewhat slower but quite complete. As shown in Figure $6 C$, the vitreous-negative "PIII" continued undiminished during the $2 \frac{1}{4}$ min period without glucose. Its amplitude was somewhat increased, but this was almost certainly the consequence of the disappearance of the vitreouspositive response of the ON-bipolar cells. Noell (1958), using intravenous iodoacetate to interrupt glycolysis, showed a marked reduction of the b-wave after only $33 \mathrm{sec}$ with a large increase in the a-wave, attributed to its being unmasked by the removal of the b-wave. Rat retina appears to differ in this regard, as Winkler (1981) observed a prompt reduction in PIII on removal of glucose.

Table 1. $\mathrm{O}_{2}$ consumption and lactate production under control conditions in darkness

\begin{tabular}{|c|c|c|c|c|}
\hline Unit & $\mathrm{O}_{2}$ consumption & Lactate production & $\begin{array}{l}\text { Glucose } \\
\text { consumed }\end{array}$ & $\begin{array}{l}\sim \mathrm{P} \\
\text { generated }\end{array}$ \\
\hline nmol $\min ^{-1}$ retina $^{-1}$ & $124 \pm 2(41)$ & $163 \pm 5(41)$ & 102.3 & 907 \\
\hline$\mu \mathrm{mol} \mathrm{min}{ }^{-1} 100 \mathrm{gm}^{-1}$ wet wt & 197 & 260 & 163 & 1442 \\
\hline$\mu \mathrm{mol} \mathrm{min}{ }^{-1} \mathrm{gm}^{-1}$ dry wt & 11.3 & 14.8 & 9.3 & 82.6 \\
\hline$\mu \mathrm{mol} \mathrm{min}{ }^{-1} \mathrm{gm}^{-1}$ protein & 27.5 & 36.3 & 22.7 & 201 \\
\hline
\end{tabular}

Experimental values for $\mathrm{O}_{2}$ consumption and lactate production are expressed as mean $\pm \mathrm{SE}$, with the number of experiments in parentheses. The amounts of glucose consumed and of $\sim \mathrm{P}$ generated have been calculated from $\mathrm{O}_{2}$ consumption and lactate production; a P:O ratio of 3 was assumed. Data have been converted from nmol min $\mathrm{mina}^{-1} \mathrm{retina}^{-1}$ to other units based on average retina having $62.7 \mathrm{mg}$ wet wt, $11 \mathrm{mg}$ dry wt, and $4.5 \mathrm{mg}$ protein. The data in this and in Table 2 were obtained on retinas perfused at $4.6 \mathrm{ml} \mathrm{min}^{-1}$ with medium equilibrated with $40 \% \mathrm{O}_{2}$. 

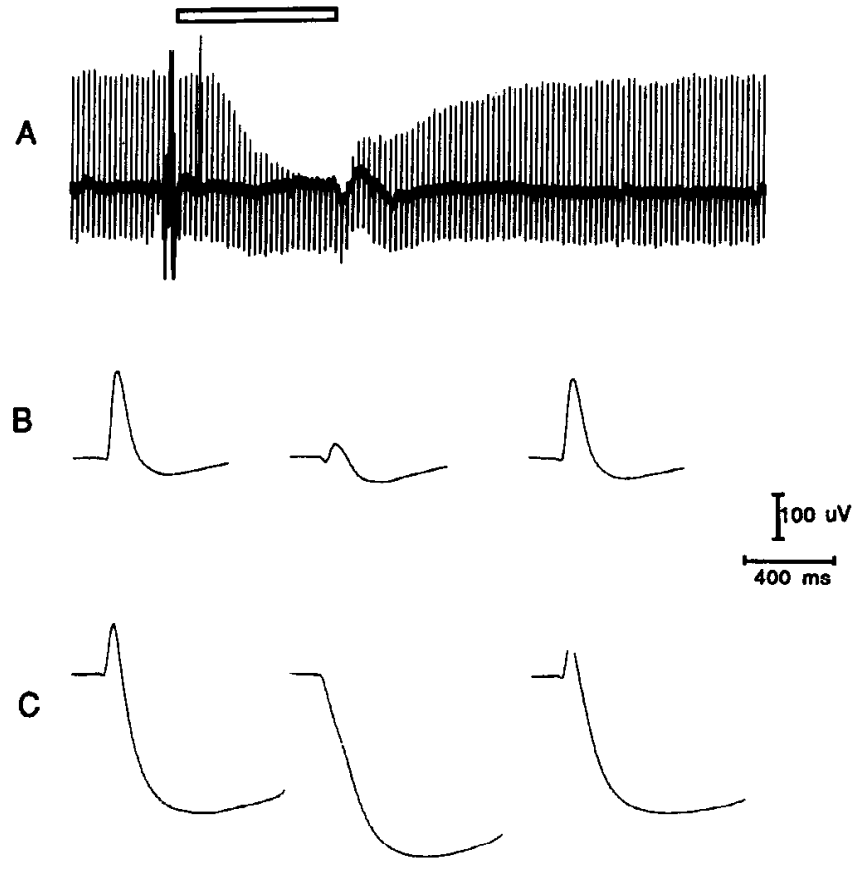

Figure 6. Effect of glucose deprivation on electrophysiological function. $A$, Response to a flash delivered every $5 \mathrm{sec}$ was used to show time course of change in amplitude of b-wave during removal of glucose (indicated by har ahove) and during its resupply. Glucose deprivation lasted $2^{1 / 4} \mathrm{~min}$. $B$ and $C$, Recordings at higher chart speed (obtained on the same retina during a previous deprivation of glucose) show b-wave $(B)$ and "PIII"' $(C)$ under control conditions $(l e f t)$, after $4 \frac{1}{2} \mathrm{~min}$ without glucose (center), and after 14 min of resupply (right). Voltage calibration applies to $A-C$; time calibration applies only to $B$ and $C$.

\section{Effect on function and energy metabolism of inhibition of $\mathrm{NaK}$ ATPase with strophanthidin}

Strophanthidin at saturating concentrations completely inhibits the active transport of $\mathrm{Na}^{+}$out of cells by NaK ATPase. Strophanthidin caused dose-related reductions in "PIII" and the b-wave, abolishing them at high concentrations (not shown), and it reduced $\mathrm{O}_{2}$ consumption and lactate production. Figure 7 shows examples of the changes in the metabolic measurements observed after the administration of a saturating, or near-saturating, concentration of strophanthidin. The recordings in Figure $7 A$ were obtained with the apparatus in the lung-bypass mode. Saturating concentrations of strophanthidin reduced $\mathrm{O}_{2}$ consumption by $49 \pm 1 \%(n=3 ; p<0.001)$ and reduced lactate production by $58 \pm 9 \%(n=2)$. This represented a reduction in $\sim$ P generation of $459 \mathrm{nmol} \mathrm{min}^{-1}$ retina $^{-1}$, or a $50 \%$ reduction in the energy normally generated (cf. Table 1). Winkler (1981) reported a $61 \%$ reduction by ouabain in the rate of aerobic glycolysis in rat retina.

The recordings shown in Figure $7 B$ were obtained with the apparatus used to measure the difference in $\mathrm{O}_{2}$ concentration in the medium, before and after it had superfused the retina. The introduction of $1 \mu \mathrm{M}$ strophanthidin caused a $50 \%$ reduction in the "arteriovenous" $\mathrm{O}_{2}$ difference, with a $t_{1 / 2}$ of $3 \mathrm{~min}$. This relatively slow response (compared, e.g., with the $t_{1 / 2}$ of $35 \mathrm{sec}$ for the response to light shown in Fig. 9) and the finding that the half-time of the response varied inversely with concentration ( $t_{1 / 2}$ of about $210 \mathrm{sec}$ with $0.15 \mu \mathrm{M}$ strophanthidin and about 75 sec with $100 \mu \mathrm{M}$ strophanthidin; not shown) are both probably
A

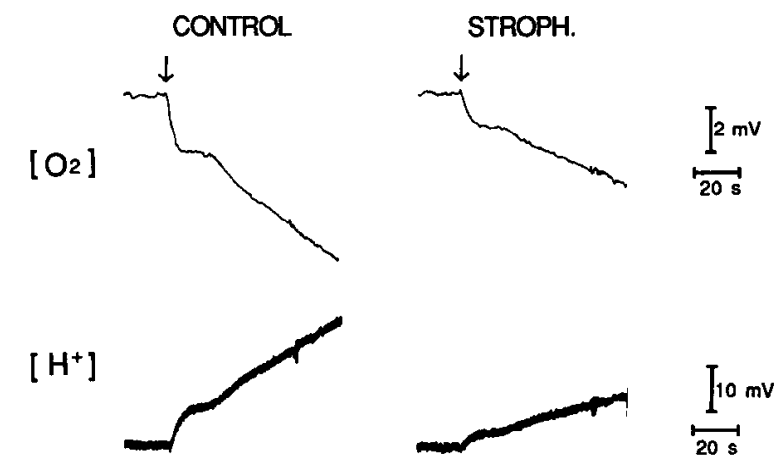

B

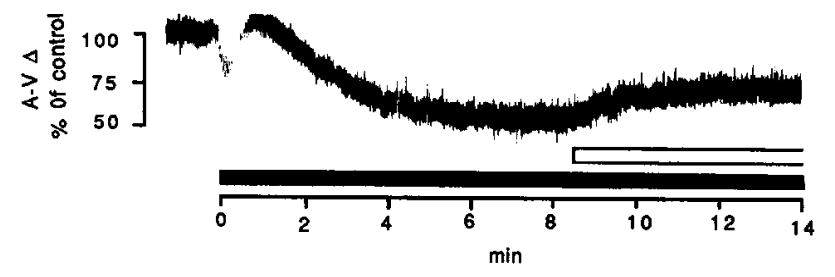

Figure 7. Effect of strophanthidin on energy metabolism. $A$, Recordings from $\mathrm{O}_{2}$ and $\mathrm{pH}$ electrodes showing fall in the $\mathrm{O}_{2}$ of the medium

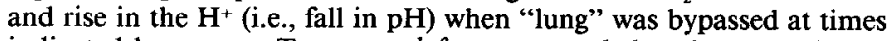
indicated by arrows. Traces on left were recorded under control conditions; traces on right were recorded $3 \mathrm{~min}$ after introduction of 100 $\mu \mathrm{M}$ strophanthidin. The initial step in the fall in $\mathrm{O}_{2}$ and rise in $\mathrm{H}^{+}$reflects the shift from "arterial" to "venous" medium following the lung bypass. Subsequent steps are markedly damped by admixing within the recirculating medium. In this experiment, $\mathrm{O}_{2}$ consumption was reduced by $48 \%$ (from 115 to $60 \mathrm{nmol} \mathrm{min}^{-1}$ retina ${ }^{-1}$ ) and the production of acid was also reduced, leading to the calculation (see Appendix) of a $68 \%$ reduction (from 143 to $46 \mathrm{nmol} \mathrm{m^{-1 }}$ retina $^{-1}$ ) in lactate production. $B$, Recording, from another retina, of the difference between the output of the arterial $\mathrm{O}_{2}$ electrode and the venous $\mathrm{O}_{2}$ electrode $(A-V \Delta)$. The introduction of $1 \mu \mathrm{M}$ strophanthidin (at the time indicated by solid bar below) caused a transient artifact followed by a reduction of $50 \%$ in the arteriovenous $\mathrm{O}_{2}$ difference $\left(t_{1 / 2}, 3 \mathrm{~min}\right)$. Steady light of about $8000 \mathrm{Rh}^{*}$ $\mathrm{sec}^{-1}$, introduced $8^{1 / 2}$ min after the strophanthidin (as indicated by open bar) caused an increase in the arteriovenous $\mathrm{O}_{2}$ difference corresponding to $18 \%$ of the $\mathrm{O}_{2}$ consumption under control conditions in darkness.

reflections of the time required for strophanthidin to inhibit the NaK ATPase.

The reductions in $\mathrm{O}_{2}$ consumption caused by strophanthidin at concentrations from 0.02 to $100 \mu \mathrm{M}$ are shown in Figure 8 . The $\mathrm{EC}_{50}$ of $0.2 \mu \mathrm{M}$ estimated from these data is similar to the $\mathrm{EC}_{50}$ of $0.28 \mu \mathrm{M}$ for the inhibition of NaK ATPase in rabbit brain microsomes obtained by Dr. K. J. Sweadner (personal communication).

\section{Energy requirements of phototransduction}

We measured the change in $\mathrm{O}_{2}$ consumption and in lactate production following a shift from steady light to darkness, or from darkness to steady light. The light used in these experiments was of an intensity (5400 $\mathrm{Rh}^{*} \mathrm{sec}^{-1}$ or more) that was sufficient to elicit a maximum PIII response and that would therefore have been expected to interrupt the dark current completely (Baylor et al., 1979).

To ensurc that the metabolic response to the dark-light shift was restricted to the photoreceptors, we blocked transmission of the light-evoked response of the photoreceptors to secondand third-order neurons with $4 \mathrm{~mm}$ aspartate or with a com- 


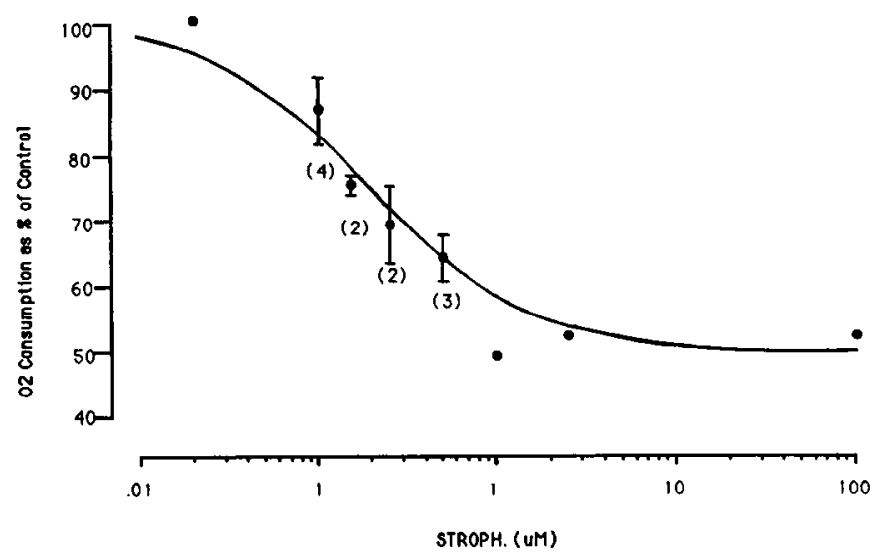

Figure 8. Dose-response curve for effect of strophanthidin on $\mathrm{O}_{2}$ consumption. $\mathrm{O}_{2}$ consumption, measured shortly after additions of strophanthidin to concentrations shown, has been plotted as percentage of consumption measured under control conditions. Line was theoretically derived to show response to an agent that has an $\mathrm{EC}_{50}$ of $0.2 \mu \mathrm{M}$ and that inhibits a process responsible for $50 \%$ of the $\mathrm{O}_{2}$ consumption.

bination of inhibitory glutamate analogs. The latter consisted of $20 \mu \mathrm{M}$ APB (an inhibiting agonist at ON-bipolars), 20 or 40 $\mu \mathrm{M}$ CNQX (an antagonist at kainate receptors), and $1000 \mu \mathrm{M}$ APV (an antagonist at NMDA receptors). These agents had been shown to act reversibly to block the $b$-wave completely and to abolish the action potentials recorded from the optic nerve in response to both the ON and OFF of light (A. Ames and Y.-Y. $\mathrm{Li}$, unpublished observations). The results showed that blocking transmission had no significant effect on the response of $\mathrm{O}_{2}$ consumption to the dark-light shift (e.g., the traces in Fig. $9 \mathrm{~A}$ were obtained without blocker and the trace in Fig. $9 B$ was obtained with $4 \mathrm{~mm}$ glutamate), and data obtained with and without transmission blockers have been combined in the following presentation of the response of $\mathrm{O}_{2}$ consumption to a steady light.

$\mathrm{O}_{2}$ consumption. As shown by representative tracings in Figure 9 , steady light caused a marked reduction in $\mathrm{O}_{2}$ consumption, measured either as a reduction in the rate of fall of medium $\mathrm{O}_{2}$ when the "lung" was bypassed (Fig. 9A) or as a reduction in the "arteriovenous" $\mathrm{O}_{2}$ difference (Fig. 9B). The average lightevoked reduction in $\mathrm{O}_{2}$ consumption, when measured under the standard conditions $\left(40 \% \mathrm{O}_{2}\right.$; flow rate of $\left.4.6 \mathrm{ml} \mathrm{min} \mathrm{min}^{-1}\right)$, was $28 \pm 2 \%$ (Table 2 ). When retinas were exposed to steady light with the $\mathrm{O}_{2}$ in the medium increased to $95 \%$, the reduction in $\mathrm{O}_{2}$ consumption was similar $(27 \pm 2 \% ; n=13)$.

The time course of the response of $\mathrm{O}_{2}$ consumption to a shift from darkness to steady light was determined using the continuous recording of the arteriovenous $\mathrm{O}_{2}$ difference as shown in Figure $9 B$. In order to correct for the time delay attributable to the apparatus, we recorded the response to an instantaneous reduction in the arteriovenous $\mathrm{O}_{2}$ difference produced by an abrupt increase in flow rate from about one-half normal up to the normal rate of $4.6 \mathrm{ml} \mathrm{min}^{-1}$ (Fig. 9B, thin trace). The time required to record the response to the change in flow rate (i.e., the time required for the flow of medium from the retina to the "venous" $\mathrm{O}_{2}$ electrode) was subtracted from the time required to record the response to light in order to obtain a more accurate estimate of the time course of the light-evoked change in the retina's $\mathrm{O}_{2}$ consumption. As evident from the example shown in Figure $9 B$, an appreciable period elapsed before there was
A

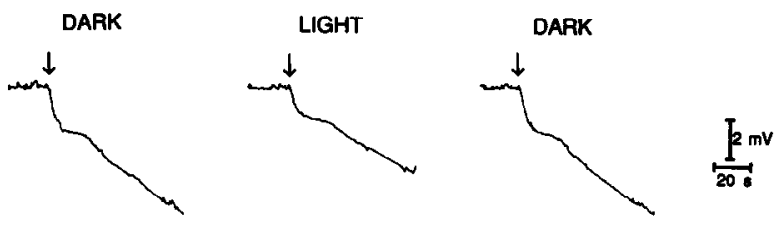

B

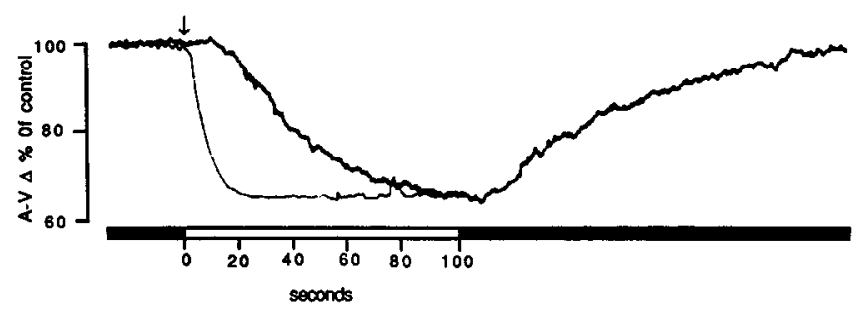

Figure 9. Effect of steady light on $\mathrm{O}_{2}$ consumption. $A$, Response of $\mathrm{O}_{2}$ electrode when "lung" was bypassed at times indicated by arrows. Recordings were made in darkness, after 2 min exposure to about 5400 $\mathrm{Rh}^{*} \mathrm{sec}^{-1}$, and $6 \mathrm{~min}$ after return to darkness. In this example, light reduced the $\mathrm{O}_{2}$ consumption by $30 \%$, from 89 to $62 \mathrm{nmol} \mathrm{min}^{-1}$ retina ${ }^{-1}$. $B$, Continuous recordings, from another retina, of the differences between the output of the "arterial" $\mathrm{O}_{2}$ electrode and the "venous" $\mathrm{O}_{2}$ electrode $(A-V \Delta)$. In this experiment, the medium was equilibrated with $95 \% \mathrm{O}_{2}$, and it contained $4 \mathrm{~mm}$ aspartate to restrict the effect of light to photoreceptors. Heavy trace shows the change in the arteriovenous difference during a $100 \mathrm{sec}$ exposure to steady light of about $5400 \mathrm{Rh}^{*} \mathrm{sec}^{-1}$, and following the return to darkness. The period of illumination is indicated by open bar at the bottom. The light reduced $\mathrm{O}_{2}$ consumption by $34 \%$. The thin trace shows the reduction in the arteriovenous difference that occurred in response to a step increase in flow to $4.6 \mathrm{ml} \mathrm{min}{ }^{-1}$, which was the rate used during the recording of the response to light. It has been superimposed on the light response so that the time of the change in flow corresponds to the time of the onset of light (both indicated by arrow), and it is used to correct the time course of the light response for the delay attributable to the apparatus (see Results).

any response of the $\mathrm{O}_{2}$ consumption to light. This absolute latency averaged $15 \pm 2 \sec (n=24)$ and the time until $50 \%$ of the maximum reduction $\left(t_{1 / 2}\right)$ was $35 \pm 2 \sec (n=24)$, both measurements having been corrected as described above for the time lag caused by the apparatus. As shown in Figure $9 B$, there was a prompt recovery of $\mathrm{O}_{2}$ consumption on return to darkness. The in vivo cat retina exhibited a similar time course for the response of $\mathrm{O}_{2}$ consumption to a change in illumination (Alder and Cringle, 1990).

The phosphodiesterase inhibitor IBMX has been shown to affect the phototransduction system in the opposite way from light by reducing the hydrolysis of cGMP and increasing the dark current (e.g., Ames and Barad, 1988). IBMX (100 $\mu \mathrm{M})$ increased $\mathrm{O}_{2}$ consumption by $13 \pm 3 \%(n=2)$ when added in darkness and by $9 \%(n=1)$ when added in steady light.

Though light acts to eliminate the energy cost of the dark current, it acts at the same time to increase the energy cost associated with the turnover of cGMP (see Discussion). In order to examine the effects of the latter, we tested the response to steady light delivered shortly after a saturating concentration of strophanthidin had been introduced to block $\mathrm{Na}^{+}$transport. As shown in Figure $7 B$, light under these circumstances caused a prompt increase in $\mathrm{O}_{2}$ consumption. In two retinas, the lightevoked increase after strophanthidin averaged $13 \pm 6 \%$ of the

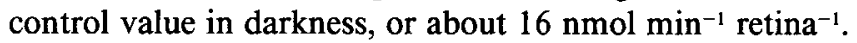


Table 2. Effect of illumination on energy metabolism

\begin{tabular}{lrllll} 
& \multicolumn{2}{l}{$\mathrm{O}_{2}$ consumption } & & \multicolumn{2}{l}{ Lactate production } \\
\cline { 2 - 3 } Illumination & \multicolumn{1}{c}{ nmol min min $^{-1}$} & $\%$ change & & \% change \\
\hline Darkness & $129 \pm 8(9)$ & & $173 \pm 9(8)$ & \\
Steady light & $93 \pm 6(9)$ & $-28 \pm 1.9(9)^{* * *}$ & & $175 \pm 11(8)$ & $+1.3 \pm 1.2(8)$ \\
Darkness & $125 \pm 4(7)$ & & $164 \pm 14(7)$ & \\
Light flash & $121 \pm 4(7)$ & $-4.0 \pm 1.9(7)^{*}$ & & $208 \pm 18(7)$ & $+27 \pm 1.6(7)^{* * *}$ \\
Darkness & $130 \pm 5(7)$ & & & $180 \pm 11(7)$ & \\
Dark flash & $119 \pm 5(7)$ & $-8.3 \pm 1.1(7)^{* * *}$ & & $206 \pm 11(7)$ & $+14.3 \pm 2.6(7)^{* *}$ \\
\hline
\end{tabular}

Data were obtained on the same retina in darkness and in one of the light conditions. Percentage change was calculated using each retina as its own control. Rates in darkness and in light, and percentage change are expressed as mean \pm SE. ${ }^{*} p<0.05 ; * * p<0.005 ; * * *<<0.001$.

Lactate production. As shown in Table 2, a shift from darkness to light (or from light to darkness) under control conditions caused no significant change in lactate production in spite of the vcry substantial changes in $\mathrm{O}_{2}$ consumption. In ordcr to see whether the energy demands of the dark current would cause an increase in glycolysis under circumstances in which $\mathrm{O}_{2}$ was limiting, we examined the effects of a light-dark shift when the availability of $\mathrm{O}_{2}$ had been reduced, by reducing the flow rate of the medium from 4.6 to $2.3 \mathrm{ml} \mathrm{min}^{-1}\left(\mathrm{O}_{2}\right.$ still $\left.40 \%\right)$. In these experiments, the response of the second- or third-order neurons to the change in illumination was blocked by the combination of glutamate analogs cited above, by $2 \mathrm{mM} \mathrm{Co}^{2+}$, or by $20 \mathrm{~mm}$ $\mathrm{Mg}^{2+}$. In some experiments, $100 \mu \mathrm{M}$ IBMX was added to the medium to enhance the increase in dark current associated with the light-dark shift (cf. Ames and Barad, 1988). Reducing the availability of $\mathrm{O}_{2}$ caused a significant $(p<0.001)$ reduction in the increase in $\mathrm{O}_{2}$ consumption associated with the light-dark shift (to $8.4 \pm 6 \% ; n=8$ ), and in each of eight such experiments, the shift from light to darkness was associated with an increase in lactate production that averaged $18.3 \pm 4 \%(p<0.005)$. On the basis of these experiments, it seems reasonable to conclude that part, at least, of the Pasteur effect shown in Figure 4 is attributable to the photoreceptors. Rat retina appears to be similar in this regard (Winkler, 1981).

\section{Energy requirements of neurotransmission through the retinal circuitry}

Several approaches were used to distinguish the changes in energy metabolism caused by changes in neurotransmission from those caused by changes in phototransduction. (1) We examined the effect on $\mathrm{O}_{2}$ consumption and lactate production of physiologically increasing neurotransmission with short flashes of light. Since light reduces the energy requirements of the photoreceptors, any increases in energy metabolism would be attributable to neurotransmission. Since the total light delivered is small comparcd to that required to block the dark current and since (under control conditions) light had little effect on photoreceptor glycolysis (see above), the amount of the change in energy metabolism (particularly of lactate production) would be expected to reflect activities involved in neurotransmission. (2) We examined the changes in energy metabolism caused by pharmacologic agents (glutamate analogs) that would be expected to block neurotransmission without affecting phototransduction. (3) We examined the change in the metabolic response to flashing light caused by agents that block transmission.

Preliminary experiments were performed to determine the flash frequency that elicited a maximum response. Using flashes of an intensity (about $2 \mathrm{Rh}^{*} \mathrm{sec}^{-1}$ ) and duration $(10 \mathrm{msec}$ ) that elicited a maximum b-wave, we varied the frequency and found that the maximum incrcase in lactate production occurred at 4 $\mathrm{Hz}$. Stimuli at $3 \mathrm{~Hz}$ gave about $80 \%$ of maximum, and stimuli at $5 \mathrm{~Hz}$ about $78 \%$ of maximum. Stimuli at $4 \mathrm{~Hz}$ had previously been found to give maximum uptake of glucose in rabbit retina, as assessed by 2-deoxyglucose (Ames et al., 1980), and the release of $\mathrm{ACh}$ has been observed to be maximal with light flashes at about this rate (Neal and Massey, 1980). Bill and Sperber (1990) demonstrated an increased 2-deoxyglucose uptake in the inner retina of the monkey in response to light flashes at $4 \mathrm{~Hz}$.

When retinas that had been in darkness were stimulated with $10 \mathrm{msec}$ light flashes at $4 \mathrm{~Hz}$, there was a prompt increase in lactate production of $27 \pm 1.6 \%(p<0.001)$ and a $4 \%$ reduction in $\mathrm{O}_{2}$ consumption (Table 2), the latter presumably reflecting the small reduction in dark current. When retinas that had been in darkness were exposed to steady light with dark flashes $(80$ msec duration, $4 \mathrm{~Hz}$ ) there was also a significant $(p<0.005)$, though somcwhat smaller, increase in lactate production and a larger reduction in $\mathrm{O}_{2}$ consumption (Table 2). A shift from steady light to steady light with dark flashes caused an increase in lactate production $(11.6 \pm 2.4 \% ; n=6 ; p<0.005)$, with little change in $\mathrm{O}_{2}$ consumption $(+0.3 \pm 1.0 \% ; n=6)$.

To examine the effects on energy metabolism of blocking neurotransmission, we used the combination of inhibitory glutamate analogs cited above (20 $\mu_{\mathrm{M}}$ APB, $20 \mu \mathrm{M}$ CNQX, 1000 $\mu \mathrm{M}$ APV) that had been shown to abolish reversibly the b-wave and light-evoked responses recorded from the optic nerve. When retinas were exposed to these agents (in darkness), there was a marked reduction in lactate production $(-44 \pm 5 \% ; n=3 ; p$ $<0.025)$ with no significant change in $\mathrm{O}_{2}$ consumption $(+1 \pm$ $2 \%$ ). In order to see whether the failure of $\mathrm{O}_{2}$ consumption to respond to the inhibition of neurotransmission was due to lack of $\mathrm{O}_{2}$ in the inner retina, we performed a few experiments under conditions designed to maximize the available $\mathrm{O}_{2} \cdot \mathrm{O}_{2}$ delivery was increased by increasing the $\mathrm{O}_{2}$ concentration from $40 \%$ to $95 \%$ and by increasing the flow rate from 4.6 to $9 \mathrm{ml} \mathrm{min}^{-1}$, and $\mathrm{O}_{2}$ consumption by the photoreceptors was reduced by using $80 \mathrm{msec}$ dark flashes $(4 \mathrm{~Hz}$ ) superimposed on a steady light of saturating intensity instead of light flashes. In two tests on a retina being maintained under these conditions, the addition of the glutamate inhibitors APB, APV, and CNQX caused a large reduction in lactate production $(32 \pm 8 \%)$ but only a small reduction in $\mathrm{O}_{2}$ consumption $(-2.9 \pm 1.2 \%)$, and in another experiment, the addition of the agonist kainate $(5 \mu \mathrm{M})$ caused a 
large increase in lactate production $(+45 \%)$ with no appreciable change $(+0.8 \%)$ in $\mathrm{O}_{2}$ consumption.

We also examined the effect of $\mathrm{Mg}^{2+}$, a less specific blocker of vesicular neurotransmission. When increased in the medium to $4.8 \mathrm{mM}$ (from the control level of $1.2 \mathrm{mM}$ ), $\mathrm{Mg}^{2+}$ promptly reduced the $\mathrm{b}$-wave (not shown), and reduced lactate production by $22 \pm 2 \%(n=4 ; p<0.005)$ without significantly affecting $\mathrm{O}_{2}$ consumption.

Agents that block neurotransmission prevented the $28 \%$ increase in lactate production that was elicited by flashing light under control conditions. If retinas had been exposed to the glutamatergic inhibitors (APB, CNQX, APV), flashing light caused no significant change in lactate production $(+1.5 \pm 2.6 \%)$, although it continued to cause a small reduction in $\mathrm{O}_{2}$ consumption $(-4.4 \pm 1.9 \%)$ similar to that seen under control conditions. After $20 \mathrm{~mm} \mathrm{Mg}{ }^{2+}$ there was also no change in lactate production in response to flashing light (one retina).

\section{Discussion}

The retinas, as expected, exhibited high-energy demands, met by both glycolysis and oxidative metabolism. The former accounted for a large fraction ( $80 \%$ ) of the glucose consumed, but only a small fraction (18\%) of the energy generated. Neurotransmission through the inner retina was dependent on glycolysis. Phototransduction was normally supported by oxidative metabolism, but used glycolytic energy when $\mathrm{pO}_{2}$ was reduced. $\mathrm{Na}^{+}$transport was, by far, the most energy-demanding single process, using about half the glycolytic energy and half the oxidative energy. Where comparison was possible, the results appeared to be consistent with those previously published.

In vivo measurements of energy metabolism in retina have been unusually difficult because of its dual blood supply. Tornquist and Alm (1979) measured arteriovenous differences and blood flow in the choroidal and retinal vasculature of pigs and calculated an $\mathrm{O}_{2}$ consumption of $224 \mu \mathrm{mol} \mathrm{min} \mathrm{m}^{-1} 100 \mathrm{gm}^{-1}(14 \%$ larger than ours) and a lactate production of $130 \mu \mathrm{mol} \mathrm{m^{-1 }}$ ( $20 \%$ less than ours). Using the same approach, Bill and Sperber (1990) calculated a value for $\mathrm{O}_{2}$ consumption for both pig and

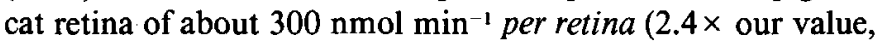
but the wet wt of the pig retinas was about $2.2 \times$ that of our rabbit retinas, and cat retina is also considerably larger than rabbit retina). Linsenmeier (1986) used $\mathrm{O}_{2}$ concentration gradients and principles of diffusion to calculate an $\mathrm{O}_{2}$ consumption for the outer retina of the cat of $313 \mu \mathrm{mol} \mathrm{min}-1100 \mathrm{gm}^{-1}$ wet weight ( $59 \%$ greater than our value, but outer retina is expected to have a higher consumption on a per gram basis than whole retina; see below). In vivo measurements of $\mathrm{O}_{2}$ consumption in human brain (e.g., Kety, 1957) have been about $21 \%$ less on a per gram basis than the measurements reported here for retina. In an in vitro study of rabbit retina (Cohen and Noell, 1960), $\mathrm{O}_{2}$ consumption was $34 \%$ less than that reported here and lactate production was 3\% less. Mcasurements of lactatc production in in vitro rat retina were $49 \%$ lower (Graymore, 1959) and 49\% higher (Winkler, 1989) than ours.

In steady state, the rate of energy metabolism can be calculated from the rate of phosphate bond hydrolysis, which in turn can be determined from the rate of phosphate labeling by $\mathrm{H}_{2}{ }^{18} \mathrm{O}$, as demonstrated by Goldberg and co-workers (Goldberg et al., 1980; Walseth et al., 1981). This technique was used to measure cGMP turnover under conditions similar to those of the present experiments, and measurements were also obtained of the ${ }^{18} \mathrm{O}$ labeling of orthophosphate and of the $\alpha-, \beta$-, and $\gamma$-phosphates of the guanine and adenine nucleotides. The rate of turnover of $\sim P$ bonds, associated with these compounds was found to total $470 \mathrm{nmol} \mathrm{min}^{-1}$ retina $^{-1}$ (Ames et al., 1986). This is $48 \%$ less than the value of $907 \mathrm{nmol} \mathrm{min}^{-1}$ obtained in the present study (Table 1). The difference between the two measurements can be largely accounted for by the fact that, in the previous study, measurements were not obtained of the ${ }^{18} \mathrm{O}$ labeling of a number of significant phosphate species, notably phosphocreatine.

\section{Phototransduction}

The responses to the several experimental variables tested were consistent in indicating that the energy required for phototransduction is derived from oxidative metabolism: light of sufficient intensity to interrupt the dark current caused a $28 \%$ reduction in the total $\mathrm{O}_{2}$ consumption of the retina; IBMX, which acts to inhibit the hydrolysis of cGMP and to increase the dark current, caused a $13 \%$ increase in $\mathrm{O}_{2}$ consumption; and deprivation of $\mathrm{O}_{2}$ caused prompt $\left(t_{1 / 2}, 5 \mathrm{~min}\right)$ loss of the light-evoked electrical response of the photoreceptors (PIII).

The remarkably high density of mitochondria in photoreceptor inner segments and the high concentration of oxidative enzymes in this layer (Lowry et al., 1956) have indicated that these cells generate an unusually large amount of oxidative energy. Several laboratories have previously reported reductions in retinal $\mathrm{O}_{2}$ consumption in response to light. In in vivo studies on cat, Linsenmeier (1986) found that light reduced the $\mathrm{O}_{2}$ consumption of the outer retina by $50 \%$, and Alder and Cringle (1990) have also reported evidence of a light-evoked reduction. In in vitro studies on frog, reductions in $\mathrm{O}_{2}$ consumption caused by light have varied from $4 \%$ to $57 \%$ (Sickel, 1972 ; Kimble et al., 1980; Zuckerman and Weiter, 1980).

The results of our experiments indicate that in the presence of adequate $\mathrm{O}_{2}$ very little, if any, of the energy required for phototransduction in the rabbit is derived from glycolysis: interruption of the dark current by light under control conditions caused no significant change in the rate of lactate production (Table 2), and as shown in Figure 6, removal of glucose from the medium caused no reduction in the light-evoked response of the photoreceptors (PIII). The results, however, also suggest that under hypoxic conditions, the photoreceptors can shift to glycolysis for energy (Pasteur effect). With the $\mathrm{O}_{2}$ supply diminished (and neurotransmission blocked), a shift from light to darkness caused only an $8 \%$ increase in $\mathrm{O}_{2}$ consumption, but under these circumstances, the light-dark shift caused a significant increase (18\%) in lactate production. A glycolytic source of energy for phototransduction probably accounts for the persistence of a small PIII ( $22 \%$ of control) $26 \mathrm{~min}$ after removal of all $\mathrm{O}_{2}$ (one retina, not shown). More of the energy for phototransduction appears to be provided by glycolysis in the rat retina (Winkler, 1981).

Though most of the energy for phototransduction is used for the active transport of the $\mathrm{Na}^{+}$that enters with the dark current, the synthesis of the high-energy phosphate bonds involved in the rapid turnover of photoreceptor cGMP also requires an appreciable amount of energy. Experiments using $\mathrm{H}_{2}{ }^{18} \mathrm{O}$ to measure phosphate bond hydrolysis have shown that $18 \mathrm{nmol} \mathrm{\textrm {min } ^ { - 1 }}$ of $\sim \mathrm{P}$ are required for cGMP turnover in darkness, and that this is increased almost fivefold in light to $83 \mathrm{nmol} \mathrm{min}^{-1}$ retina $^{-1}$ (Ames et al., 1986). The dark-light increase of $65 \mathrm{nmol} \mathrm{\textrm {min } ^ { - 1 }}$ retina $^{-1}$ would correspond (assuming a $\mathrm{P}: \mathrm{O}$ ratio of 3 ) to an

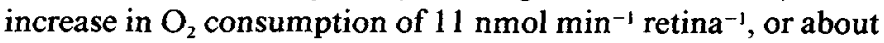
$9 \%$ of the control value in darkness. In the present experiment, 
when the transport of $\mathrm{Na}^{+}$due to the dark current was blocked by strophanthidin, light caused a $13 \%$ increase in $\mathrm{O}_{2}$ consumption. A light-evoked increase in retinal $\mathrm{O}_{2}$ consumption has been observed after ouabain (Kimble et al., 1980). It also has been observed after switching to an $\mathrm{Na}^{+}$-free medium but not in the presence of IBMX, which supports the interpretation that is related to cGMP metabolism (Haugh et al., 1991).

It is clear that the light-evoked decrease in $\mathrm{O}_{2}$ consumption observed under control conditions represents the net effect of an increase due to cGMP turnover and a larger decrease duc to interruption of the dark current. In order to obtain a better estimate of the energy cost of the dark current itself, the lightevoked increase in $\mathrm{O}_{2}$ consumption attributable to cGMP turnover should be added to the net decrease as observed under control conditions. We used the light-evoked increase in consumption observed after strophanthidin (13\% of the control value in darkness) as an estimate of the former and added this to the $28 \%$ (Table 2) decrease observed under control conditions, to estimate that the dark current accounted for $41 \%$ of the retina's $\mathrm{O}_{2}$ consumption in darkness. This corresponds to $52 \mathrm{nmol}$ min $^{-1}$ retina $^{-1}$ of $\mathrm{O}_{2}$ and to the generation of $312 \mathrm{nmol} \mathrm{min} \mathrm{n}^{-1}$ retina $^{-1}$ of $\sim \mathrm{P}$. This is about $35 \%$ of the total energy production of the retina and about $86 \%$ of oxidative energy used by $\mathrm{NaK}$ ATPase. It thus appears that the great majority of the $\mathrm{NaK}$ ATPase in the retina that is energized by oxidative metabolism is involved in the active transport of $\mathrm{Na}^{+}$out of photoreceptors. From the work of McGrail and Sweadner (1989) the isozyme of NaK ATPase responsible is $\alpha 3$.

\section{Neurotransmission through retinal circuits}

The results indicate that the energy for neurotransmission through the retina is provided by glycolysis: light flashes at $4 \mathrm{~Hz}$ increased lactate production by $27 \%$, whereas they caused a $4 \%$ decrease in $\mathrm{O}_{2}$ consumption (attributable to a small reduction in the dark current); selective blockers of neurotransmission (APB, CNQX, APV) reduced lactate production by $44 \%$ without significantly affecting $\mathrm{O}_{2}$ consumption; $\mathrm{Mg}^{2+}$, which acts more generally to block neurotransmission, also caused marked reductions in lactate production with little effect at low concentrations on $\mathrm{O}_{2}$ consumption; and removal of glucose from the medium caused a surprisingly rapid ( $t_{1 / 2}<1 \mathrm{~min}$ ) loss of neurotransmission as assessed by the b-wave without affecting phototransduction as assessed by PIII.

There appear to be three possible interpretations of these findings: (1) the inner retina was abnormally hypoxic under the conditions of our experiments, (2) the inner retina is normally hypoxic and has adapted its energy metabolism accordingly, or (3) processes involved in neurotransmission are linked obligatorily to glycolysis. The first seems unlikely; even with $\mathrm{O}_{2}$ concentration more than doubled, with the rate of flow of medium doubled, and with the $\mathrm{O}_{2}$ consumption of the photoreceptors reduced with light, agents affecting the glutamatergic transmission caused large changes in lactate production and relatively small changes in $\mathrm{O}_{2}$ consumption. The second alternative is almost certainly at least partially responsible for the findings. $\mathrm{O}_{2}$ concentration in the inner retina can be calculated to be markedly reduced by diffusion limitations, and measurements in vivo have supported these calculations (e.g., Linsenmeier, 1986). Microchemical analysis has shown high concentrations of glycolytic enzymes in the inner retina (Lowry et al., 1956). The third possibility - an obligatory dependence of specific functions on glycolytic rather than oxidative energy - cannot be crit- ically assessed with the data obtained in the present experiments but deserves serious consideration. Noell (1958) cited evidence for it in photoreceptor cells, and it appears to be true of smooth muscle (e.g., Paul et al., 1989) and perhaps brain (Lipton and Robacker, 1983; Lear and Ackermann, 1989).

\section{Response to phasic stimuli}

Neurons in CNS sensory systems characteristically respond to stimuli in a phasic fashion - a result either of negative feedback loops or of rapid inactivation of rcceptors. This was exemplified by compound action potentials recorded from the optic nerve stump of the isolated rabbit retina, in which the response to the ON of a 1 sec light pulse peaked after $31 \mathrm{msec}$ but fell to $50 \%$ of maximum after an additional $29 \mathrm{msec}$ and the response to the OFF peaked after $29 \mathrm{msec}$ but fell to $50 \%$ after an additional $21 \mathrm{msec}$ (not shown; experiments performed at $30^{\circ} \mathrm{C}$ ). The transient nature of the responses of the neurons of the inner retina presumably explains why phasic stimuli of up to $4 \mathrm{~Hz}$-either light flashes or dark flashes-caused the largest increases in lactate production. On the basis of the time course of the ganglion cell responses cited above and the relatively high stimulus frequencies that CNS neurons in general are able to follow, one would have expected the positive correlation between lactate production and flash frequency to have been sustained as the frequency was increased above $4 \mathrm{~Hz}$. The falloff in lactate production observed at frequencies greater than $4 \mathrm{H} z$ probably reflected the limitations of the temporal resolution of the phototransduction process, which resulted in smaller changes in photoreceptor transmitter release at higher frequency signals. This may provide a protective limit to the maximal energy demands that can be imposed on the neurons of the inner retina (see below).

\section{Relation of glucose uptake to energy metabolism}

In tissucs in which both glycolytic and oxidative mechanisms are used to generate energy, measurements of glucose uptake will not accurately reflect changes in the amount of energy being used if there is a change in the proportion of glycolytic to oxidative metabolism. For example, as shown in Table 2, the shift from darkness to steady light with dark flashes caused an increase in lactate production of $26 \mathrm{nmol} \mathrm{min} \mathrm{m}^{-1}$, but a decrease

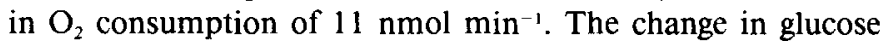
uptake can be calculated to have been a net increase of 11.2 nmol $\min ^{-1}(26 / 2-11 / 6)$, whereas the change in $\sim P$ generated can be calculated to have been a net decrease of $40 \mathrm{nmol} \mathrm{min} \mathrm{m}^{-1}$ $(26-11 \times 6)$. Problems of this sort (though probably less extreme) may cause difficulties in interpreting changes in 2-deoxyglucose uptake in other portions of the CNS (cf. Ackermann and Lear, 1989).

\section{Rate of turnover of intracellular $\mathrm{Na}^{+}$}

From the amount of the reduction in energy usage following the administration of a saturating concentration of strophanthidin, we estimated (as described above) that the total energy requirement of retinal NaK ATPase in darkness was $459 \mathrm{nmol} \sim \mathrm{P}$ $\mathrm{min}^{-1}$ retina ${ }^{-1}$. Since three $\mathrm{Na}^{+}$ions are transported out of the cell for each $\sim \mathrm{P}$ used by NaK ATPase, one can further estimate that $1377 \mathrm{nmol}$ of $\mathrm{Na}^{+}$was being actively transported out of the cells each minute. The total intracellular $\mathrm{Na}^{+}$in rabbit retina has been measured (Ames and Nesbett, 1966) to be $90 \mathrm{nmol}$ $\mathrm{mg}^{-1}$ dry weight, or about $990 \mathrm{nmol}$ retina $^{-1}$. Combining these measurements, we estimate the $k_{o}$ for $\mathrm{Na}^{+}$(fraction of intracel- 


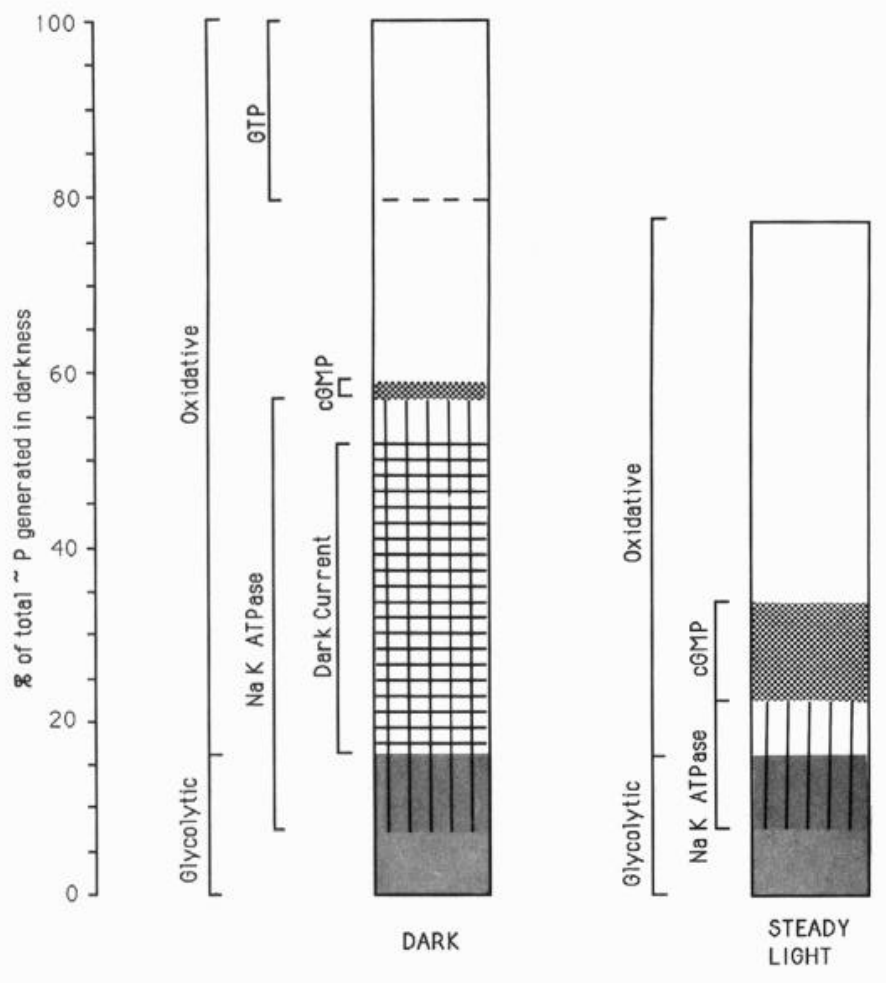

Figure 10. Summary of data on energy generation and usage in darkness and steady light, calculated in terms of $\sim P$ and expressed as percentages of total energy generation in darkness. Energy from glycolysis (shaded portion; $16 \%$ in darkness and light) calculated from lactate production. Energy from oxidative metabolism (unshaded remainder, $84 \%$ in darkness and $61 \%$ in light) calculated from $\mathrm{O}_{2}$ consumption assuming P:O ratio of 3). Energy used by NaK ATPase (vertical lines; $50 \%$ in darkness and $15 \%$ in light) was estimated in darkness from the reductions in lactate production and $\mathrm{O}_{2}$ consumption caused by a saturating concentration of strophanthidin. The effect of strophanthidin in light was not measured, and the energy used by NaK ATPase in light was estimated by assuming it was the same as in darkness, less the energy used by dark current. Energy required for cGMP turnover (stippled area; $2 \%$ in darkness and $11 \%$ in light) was calculated from the light-evoked increase in $\mathrm{O}_{2}$ consumption after strophanthidin and from data acquired in a previous study (Ames et al., 1986). Energy for dark current (horizontal lines; $35 \%$ in darkness and $0 \%$ in light) was estimated from light-evoked decrease in $\mathrm{O}_{2}$ consumption corrected for energy requirements of light-evoked increase in cGMP turnover. Energy transfer involving $\gamma$-phosphate of GTP (20\%) was measured in darkness in a previous study (Goldberg et al., 1983). In the model presented here, all energy for NaK ATPase is assumed to come from ATP.

lular $\mathrm{Na}^{+}$effluxing per minute) to be $1.39 \mathrm{~min}^{-1}$ and the $t_{1 / 2}$ for $\mathrm{Na}^{+}$efflux $\left(\ln 2 / k_{o}\right)$ to be $0.5 \mathrm{~min}$.

$\mathrm{Na}^{+}$efflux from retinal cells has been determined previously, and somewhat more directly, in experiments that measured the rate of elution of ${ }^{24} \mathrm{Na}$ from intracellular fluid (Ames et al., 1976), and the $t_{1 / 2}$ for $\mathrm{Na}^{+}$efflux was found by this method to be 0.8 $\min$. Since no correction was made for the reuptake of the eluting ${ }^{24} \mathrm{Na}$ (like the correction made for leucine in the same study), the actual $t_{1 / 2}$ for efflux of $\mathrm{Na}^{+}$from the cells was presumably somewhat less than $0.8 \mathrm{~min}$. The agreement between these two very different measures of $\mathrm{Na}^{+}$turnover appears to be moderately good.

Additional evidence for a rapid turnover of intracellular $\mathrm{Na}^{+}$ was obtained in the present experiments from the rate of the response of $\mathrm{O}_{2}$ consumption to interruption of the dark current by steady light (Fig. 9B), and from the rate of the response of the b-wave to glucose deprivation (Fig. 6A). In both cases, the time course of the response probably reflected the time course of a change in intracellular $\mathrm{Na}^{+}$. In the first case, the reduction in $\mathrm{O}_{2}$ consumption $\left(t_{1 / 2}, 35 \mathrm{sec}\right)$ followed the reduction in the energy requirements of photoreceptor NaK ATPase, which in turn reflected the reduction in intracellular $\mathrm{Na}^{+}$(to about onethird of the dark level; cf. Somlyo and Walz, 1985). In the second case, the failure of the b-wave $\left(t_{1 / 2}, 55 \mathrm{sec}\right)$ probably reflected a large (? several-fold) rise in bipolar cell intracellular $\mathrm{Na}^{+}$in the absence of glycolytic energy.

Thus, several different types of measurements appear to be consistent in indicating that the turnover of intracellular $\mathrm{Na}^{+}$ in retina is rapid, with a $t_{1 / 2}$ of between 0.5 and $1 \mathrm{~min}$.

\section{Energy demands of function versus energy reserves}

There was a high level of energy metabolism even in the resting retina attributable in large part to energy-demanding processes that are required to maintain the neurons in an excitable state, and physiological activation of the retinal cells caused dramatic additional increases in their energy demands. Thus, in retinas in which neurotransmission was activated by flashing light, lactate production was 2.3-fold greater than in retinas in which neurotransmission had been slowed by inhibitory glutamate analogs, and the oxidative energy required by the dark current represented a $57 \%$ increase in the oxidative energy used in light. Since these fractional changes are calculated in relation to the total retina's metabolism, the fractional change within the cell type involved in a particular function must have been very large. From these considerations, it seems likely that maximal levels of physiological activity may severely tax the ability of the neurons to supply energy, and that imbalances between supply and demand may at times limit the physiological response.

Because of the large energy requirements of retina, energy reserves would also have to be large to maintain function following an interruption of supply. This appeared not to be the case. The b-wave began to fail $30 \mathrm{sec}$ after removal of glucose, and PIII began to fail $60 \mathrm{sec}$ after removal of $\mathrm{O}_{2}$. Hypothermia has been used successfully to protect CNS tissues from a reduction in energy supply (e.g., Young et al., 1983; Busto et al., 1987). Lowering the temperature of the retina caused parallel reductions in function and energy usage of almost $7 \%$ per degree (Fig. 3), the latter presumably a consequence of the former. On the basis of the temperature coefficients, a reduction of $4^{\circ} \mathrm{C}$ in temperature would be expected to provide continuing protection against a reduction of almost one-third in the supply of energy.

\section{Energy accounting}

By relating the energy generated by the retina to the known energy requirements, it is possible to undertake a rather speculative energy accounting as shown in Figure 10. No great discrepancy was apparent with respect to glycolysis. Glycolysis accounted for $18 \%$ of the total energy generated by the retina in darkness, and of this, $58 \%$ was used for the transport of $\mathrm{Na}^{+}$ (as assessed by the response to strophanthidin). There appears to be no difficulty in ascribing the remaining $42 \%$ to the transport of other ions, to other processes involved in physiological functioning, or to vegetative metabolism.

However, a serious discrepancy does seem to arise with respect to energy generated by oxidative metabolism. About $49 \%$ of the oxidative energy generated in darkness was used by $\mathrm{NaK}$ ATPase and another $2 \%$ can be ascribed to the turnover of cGMP, which is relatively small in darkness. This leaves $49 \%$ 
unaccounted for, representing about $360 \mathrm{nmol} \sim \mathrm{P} \min ^{-1}$. A

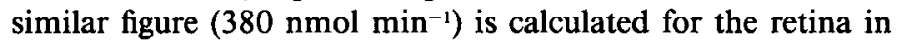
light, when the energy requirements of the dark current are negligible, but when total $\mathrm{O}_{2}$ consumption is lower and the energy cost of cGMP turnover is higher. Thus, as shown by the open portions of the bars in Figure 10, we are unable to assign any use for about half of the total energy generated by the retina. It appears not to be used for $\mathrm{Na}^{+}$transport, for cGMP turnover, or for neurotransmission through the inner retina (since neither stimulation with flashing light nor inhibition by the glutamate analogs had a significant effect on $\mathrm{O}_{2}$ consumption). Very little of it can be ascribed to the anabolic or "vegetative metabolism" of the retina. Protein synthesis is generally considered to be the most energy-demanding anabolic process. Rabbit retina contains about $4.5 \times 10^{6} \mathrm{ng}$ of protein made up of $32 \times 10^{3} \mathrm{nmol}$ of amino acid (average MW about 140), of which $0.55 \%$ (Parks et al., 1976) or $176 \mathrm{nmol}$ are being replaced per hour, or 2.9 $\mathrm{nmol} \mathrm{min}{ }^{-1}$. The energy cost is $4 \sim \mathrm{P}$ per peptide bond or about $12 \mathrm{nmol} \sim \mathrm{P} \mathrm{m^{-1 }}$ retina $^{-1}$. This represents only $1.3 \%$ of the energy being generated. Estimates of the energy cost for the synthesis of nucleic acids and phospholipids, based on published values for their turnover, are even less.

It seems likely that a large portion of the unaccounted for oxidatively derived energy is being generated in the photoreceptors. It may be being used for the active transport of $\mathrm{Ca}^{2+}$ (for which energy costs have not yet been established). It may be related to the remarkably high turnover of the $\gamma$-phosphate of GTP. Labeling experiments with $\mathrm{H}_{2}{ }^{18} \mathrm{O}$ have shown that the $\gamma$-phosphate of GTP in rabbit retina is being replaced at the rate of $10 \%$ per second (Goldberg et al., 1983; Table 1), and

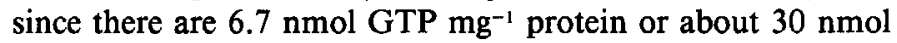
of GTP in a retina (Goldberg et al., 1983), this represents a turnover of $3 \mathrm{nmol} \sim \mathrm{P}$ per second or $180 \mathrm{nmol} \sim \mathrm{P}$ per minute, which corresponds to $20 \%$ of the entire energy production of the retina (or half of the unaccounted for oxidatively derived $\sim \mathrm{P})$. Remarkably, the $\mathrm{H}_{2}{ }^{18} \mathrm{O}$ labeling studies showed the rate of replacement of the $\gamma$-phosphate of GTP to be similar to the rate of replacement of the $\gamma$-phosphate of ATP when both are expressed as nmol sec ${ }^{-1}$ retina $^{-1}$. To our knowledge, no reaction requiring this much energy transfer involving the $\gamma$-phosphate bond of GTP has been identified.

\section{Appendix}

Measurement of $\mathrm{O}_{2}$ consumption

The concentration ( $\mathrm{mM}$ ) of $\mathrm{O}_{2}$ in medium equilibrated with the gas phase at $37^{\circ} \mathrm{C}$ was calculated from the following equation:

$$
\left[\mathrm{O}_{2}\right]=0.02273 / 0.0224 \times(760-47) / 760 \times \% \mathrm{O}_{2}
$$

in which 0.02273 is the solubility coefficient, or the milliliters (STP) of $\mathrm{O}_{2}$ dissolved in $1 \mathrm{ml}$ of saline at $37^{\circ} \mathrm{C}$ with the $\mathrm{O}_{2}$ pressure in the gas phase $760 \mathrm{mmHg}$ (Altman and Dittmer, 1971); 0.0224 is the volume (ml) of gas (STP) containing $1 \mu \mathrm{mol}$; 47 is the vapor pressure $(\mathrm{mmHg})$ of water at $37^{\circ} \mathrm{C}$; and $\% \mathrm{O}_{2}$ is the fraction of $\mathrm{O}_{2}$ in the dry gas. Thus, the $\mathrm{O}_{2}$ concentration under our standard conditions $\left(40 \% \mathrm{O}_{2}, 37^{\circ} \mathrm{C}\right)$ was $0.381 \mathrm{~mm}$.

The system used to record the output of the Clark $\mathrm{O}_{2}$ electrodes was adjusted, before the retina was placed in the heartlung apparatus, to give a zero response with no $\mathrm{O}_{2}$ and a $50 \mathrm{mV}$ response when the medium was equilibrated at $37^{\circ} \mathrm{C}$ with a gas phase containing $40 \% \mathrm{O}_{2}$. A reduction of $1 \mathrm{mV}$ in the electrode's response then indicated a reduction of $7.62 \times 10^{-3} \mu \mathrm{mol} \mathrm{ml}^{-1}$
$(0.381 / 50)$ in the $\mathrm{O}_{2}$ in the medium. Since $\mathrm{O}_{2}$ is consumed by the reaction that provides the reading, there is a (small) reduction in the $\mathrm{O}_{2}$ in the fluid in contact with the electrode, particularly if the medium flow is slow. Therefore, electrode sensitivities were set at the flow rate (usually $4.6 \mathrm{ml} \mathrm{min}^{-1}$ ) to be used in the experiment. The electrode sensitivity also varies with temperature, increasing $3.7 \%$ for each $1{ }^{\circ} \mathrm{C}$ rise (primarily because of the increase with temperature in the $\mathrm{O}_{2}$ permeability of the Teflon membrane separating the platinum electrode from the medium). The temperature $(T)$ of the medium was therefore recorded at the time of each reading, and the readings were corrected to $37^{\circ} \mathrm{C}$ by the factor $e^{0.037(37-T)}$.

Most of the measurements of $\mathrm{O}_{2}$ consumption were obtained by bypassing the "lung" and measuring the fall in $\mathrm{O}_{2}$ over 1 min in the $2.3 \mathrm{ml}$ of recirculating medium (see Figs. $7 A, 9 A$ ).

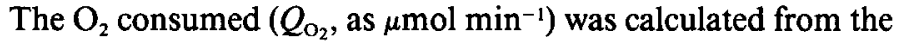
change in the output of the arterial $\mathrm{O}_{2}$ electrode after $1 \mathrm{~min}$ $(\Delta \mathrm{mV})$ using the following equation, which incorporates the factors presented above:

$$
Q_{\mathrm{O}_{2}}=\Delta \mathrm{mV} \times 2.3 \times e^{0.037(37-T)} \times 7.62 \times 10^{-3}
$$

Under control conditions, $\Delta \mathrm{mV}$ was about $7 \mathrm{mV}$. This represents a $17.5 \%$ reduction in the medium $\mathrm{O}_{2}$ and leads to the

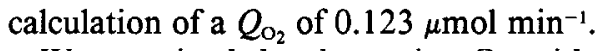

We examined the change in $\mathrm{pO}_{2}$, with the "lung" bypassed and no tissue in the chamber, and found it to be small. Under control conditions $\left(40 \% \mathrm{O}_{2}\right)$, the change attributable to the apparatus was less than $1 \%$ of the change caused by the tissue and was very constant. If the medium had been equilibrated with $\mathrm{O}_{2}$ at tensions very different from room air (e.g., $95 \%$ or $0 \%$ ), there were losses or gains of $\mathrm{O}_{2}$ when the "lung" was bypassed that became significant, and corrections were applied based on measurements made without the retina.

When it was important to follow the time course of the response, $\mathrm{O}_{2}$ consumption was determined by continually measuring the "arteriovenous" differences with the "lung" in the circuit (see Figs. $7 B, 9 B$ ). For this purpose, the recording system was adjusted to display the difference between the outputs of the arterial and venous electrodes. The same factor was used to convert $\mathrm{mV}$ to $\mu \mathrm{mol} \mathrm{ml}^{-1}$, and the "arteriovenous" concentration difference was multiplied by the flow rate to obtain $Q_{\mathrm{O}_{2}}$.

Since parts of the apparatus were made of acrylate and silicone rubber into which (and out of which) $\mathrm{O}_{2}$ can diffuse, large changes in the concentration of $\mathrm{O}_{2}$ in the medium caused by changing the percentage $\mathrm{O}_{2}$ in the gas phase were followed temporarily by movements of $\mathrm{O}_{2}$ between apparatus and medium that could be significant compared with the rate of $\mathrm{O}_{2}$ consumption by the retina. It was therefore necessary to allow a $30 \mathrm{~min}$ period for reequilibration after changing the $\mathrm{O}_{2}$ in the gas phase.

\section{Calculation of lactate production}

The bicarbonate buffer, which is the principal buffer of the medium, becomes relatively ineffective when the medium is out of contact with the gas phase, as it was during measurements of lactate production. This has the advantage that small additions of acid cause easily measured reductions in $\mathrm{pH}$ (see Fig. $7 A$ ), but it requires that the role of the phosphate buffer (usually negligible) be taken into account in the calculations.

The buffering status of the medium, before a lung bypass was instituted and when the medium was still equilibrated with the gas phase containing $5 \% \mathrm{CO}_{2}$, is characterized by the following equation (all concentrations are in $\mathrm{mM}$ ): 


$$
\mathrm{pH}=6.1+\log \frac{22.6}{1.105}=6.9+\log \frac{0.3822}{0.1178}=7.411,
$$

in which 6.1 is the $p \mathrm{~K}_{1}{ }^{\prime}$ for $\mathrm{H}_{2} \mathrm{CO}_{3} ; 22.6$ is the concentration of $\mathrm{HCO}_{3}^{-;}, 1.105$ is the concentration of dissolved $\mathrm{CO}_{2}$ and $\mathrm{H}_{2} \mathrm{CO}_{3}$, obtained as the product of Henry's constant $(0.031)$ and the partial pressure of $\mathrm{CO}_{2}$ in the gas phase $[0.05 \times(760-47)=$ $35.65 \mathrm{mmHg}$ ]; 6.9 is the $p \mathrm{~K}_{2}{ }^{\prime}$ for $\mathrm{H}_{3} \mathrm{PO}_{4} ; 0.3822$ is the concentration of $\mathrm{HPO}_{4}{ }^{2-}$; and 0.1178 is the concentration of $\mathrm{H}_{2} \mathrm{PO}_{4}{ }^{-}$.

The buffering status after $1 \mathrm{~min}$ of lung bypass is shown by the following equation, which indicates the changes caused by the $\mathrm{CO}_{2}$ and lactic acid released into the $2.3 \mathrm{ml}$ of recirculating medium that had no contact with the gas phase:

$$
\begin{aligned}
\mathrm{pH}_{t} & =7.411-\Delta \mathrm{pH} \\
& =6.1+\log \frac{22.6-[A]}{1.105+\left[Q_{\mathrm{O}_{2}} / 2.3\right]+[A]} \\
& =6.9+\log \frac{0.3822-[B]}{0.1178+[B]}
\end{aligned}
$$

in which $\Delta \mathrm{pH}$ is the measured fall in $\mathrm{pH} ; Q_{\mathrm{O}_{2}}$ is the $\mathrm{O}_{2}$ consumed in $1 \mathrm{~min}$ (in $\mu \mathrm{mol}$ ), and $\left[Q_{\mathrm{O}_{2}} / 2.3\right]$ is the concentration (in $\mathrm{mM}$ ) of dissolved $\mathrm{CO}_{2}$ and $\mathrm{H}_{2} \mathrm{CO}_{3}$ produced; and $[A]+[B]$ is the concentration of lactic acid generated in $1 \mathrm{~min}$. This equation assumes an RQ of 1 and further assumes that exchanges between retina and medium having a significant effect on $\mathrm{pH}$ are limited to the release of $\mathrm{CO}_{2}$ and lactate.

The above equation was rearranged as follows to solve for the concentration of lactic acid, which multiplied by the volume

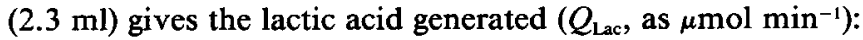

$$
\begin{aligned}
Q_{\text {Lac }}= & 2.3([A]+[B]) \\
=2.3( & \frac{22.6-\left(1.105+Q_{\mathrm{O}_{2}} / 2.3\right) \operatorname{antilog}(1.311-\Delta \mathrm{pH})}{1+\operatorname{antilog}(1.311-\Delta \mathrm{pH})} \\
& \left.+\frac{0.3822-0.1178 \operatorname{antilog}(0.511-\Delta \mathrm{pH})}{1+\operatorname{antilog}(0.511-\Delta \mathrm{pH})}\right) .
\end{aligned}
$$

A typical retina under control conditions consumed $0.12 \mu \mathrm{mol}$ of $\mathrm{O}_{2}$ in $1 \mathrm{~min}$ and caused a fall in medium $\mathrm{pH}$ of 0.044 units in $1 \mathrm{~min}$, leading to the calculation of a lactic acid production of $0.163 \mu \mathrm{mol} \mathrm{min} \mathrm{m}^{-1}$.

The $\mathrm{pH}$ electrode used for these measurements was calibrated under the conditions of the experiment, but without the retina in the apparatus, by increasing the $\mathrm{CO}_{2}$ from $5 \%$ to $10 \%$ or by adding a known concentration of fixed acid to the medium. Its sensitivity remained very constant, even from day to day.

\section{References}

Ackermann RF, Lear JL (1989) Glycolysis-induced discordance between glucose metabolic rates measured with radiolabeled fluorodeoxyglucose and glucosc. J Cercb Blood Flow Metab 9:774-785.

Alder VA, Cringle SJ (1990) Vitreal and retinal oxygenation. Graefe's Arch Clin Exp Ophthalmol 228:151-157.

Altman PL, Dittmer DS, eds (1971) FASEB handbook of respiration and circulation, $p$ 18. Bethesda, MD: Federation of American Societies for Experimental Biology.

Ames A III, Barad M (1988) Metabolic flux of cyclic GMP and phototransduction in rabbit retina. J Physiol (Lond) 406:163-179.

Ames A III, Nesbett FB (1966) Intracellular and extracellular compartments of mammalian central nervous tissue. J Physiol (Lond) $184: 215-238$.
Ames A III, Nesbett FB (1981) In vitro retina as an experimental model of the central nervous system. J Neurochem 37:867-877.

Ames A III, Parks JM, Nesbett FB (1976) Transport of leucine and sodium in central nervous tissue: studies on retina in vitro. $\mathrm{J}$ Neurochem 27:999-1015.

Ames A III, Parks JM, Nesbett FB (1980) Synthesis and degradation of retinal proteins in darkness and during photic stimulation. J Neurochem 35:143-148.

Ames A III, Walseth TF, Heyman R, Barad M, Graeff RM, Goldberg ND (1986) Light-induced increases in cGMP metabolic flux correspond with electrical responses of photoreceptors. J Biol Chem 261: 13034-13042.

Baylor DA, Lamb TD, Yau K-W (1979) The membrane current of single rod outer segments. J Physiol (Lond) 288:589-611.

Baylor DA, Matthews G, Yau K-W (1982) Temperature effects on the membrane current of the retinal rods of the toad. J Physiol (Lond) 337:723-734.

Bill A, Sperber GO (1990) Aspects of oxygen and glucose consumption in the retina: effects of high intraocular pressure and light. Graefe's Arch Clin Exp Ophthalmol 228:124-127.

Busto R, Dietrich WD, Globus MY-T, Valdes I, Scheinberg P, Ginsberg MD (1987) Small differences in intraischemic brain temperature critically determine the extent of ischemic neuronal injury. J Cereb Blood Flow Metab 7:729-738.

Cohen LH, Noell WK (1960) Glucose catabolism of rabbit retina before and after development of visual function. J Neurochem 5:253276.

Craig FN, Beecher HK (1943) The effect of low oxygen tension on tissue metabolism (retina). J Gen Physiol 26:467-472.

Field J II, Fuhrman FA, Martin AW (1944) Effect of temperature on the oxygen consumption of brain tissue. J Neurophysiol 7:117-126.

Goldberg ND, Walseth TF, Stephenson JH, Krick TP, Graeff G (1980) ${ }^{18} \mathrm{O}$ labeling of guanosine monophosphate upon hydrolysis of cyclic guanosine $3^{\prime}: 5^{\prime}$-monophosphate by phosphodiesterase. J Biol Chem 255:10344-10347.

Goldberg ND, Ames A III, Gander JE, Walseth TF (1983) Magnitude of increase in retinal cGMP metabolic flux determined by ${ }^{18} \mathrm{O}$ incorporation into nucleotide alpha-phosphoryls corresponds with intensity of photic stimulation. J Biol Chem 258:9213-9219.

Graymore C (1959) Metabolism of the developing retina. 1. Aerobic and anaerobic glycolysis in the developing rat retina. $\mathrm{Br}_{\mathrm{J}} \mathrm{J}$ Ophthalmol 43:34-39.

Hagerdal M, Harp J, Nilsson L, Siesjo BK (1975) The effect of induced hypothermia upon oxygen consumption in the rat brain. J Neurochem 24:311-316.

Haugh LM, Griff ER, Linsenmeier RA (1991) Light-evoked oxygen responses in the isolated toad retina. Invest Ophthalmol Vis Sci 32: 671.

Kety SS (1957) The general metabolism of the brain in vivo. In: Metabolism of the nervous system (Richter D, ed), pp 221-237. London: Pergamon.

Kimble EA, Svobada RA, Ostroy SE (1980) Oxygen consumption and ATP changes of the vertebrate photoreceptor. Exp Eye Res 31:271288.

Lear JL, Ackermann RF (1989) Why the deoxyglucose method has proven so useful in cerebral activation studies: the unappreciated prevalence of stimulation-induced glycolysis. J Cereb Blood Flow Metab 9:911-913.

Linsenmeier RA (1986) Effects of light and darkness on oxygen distribution and consumption in the cat retina. J Gen Physiol 88:521542.

Linsenmeier RA (1990) Electrophysiological consequences of retinal hypoxia. Graefe's Arch Clin Exp Ophthalmol 228:143-150.

Lipton P, Robacker K (1983) Glycolysis and brain function: $\left[\mathrm{K}^{+}\right]_{o}$ stimulation of protein synthesis and $\mathrm{K}^{+}$uptake require glycolysis. FASEB J 42:2875-2880.

Lowry OH, Roberts NR, Lewis C (1956) The quantitative histochemistry of the retina. J Biol Chem 220:879-892.

Lucas DR (1962) In vitro maintenance of the mature guinea-pig retina. Vision Res 2:35-41.

McCulloch J, Saraki HE, Jehle J, Sokoloff L (1982) Local cerebral glucose utilization in hypothermic and hyperthermic rats. J Neurochem 39:255-258.

McGrail KM, Sweadner KJ (1989) Complex expression patterns for $\mathrm{Na}^{+}, \mathrm{K}^{+}$-ATPase isoforms in retina and optic nerve. Eur $\mathrm{J}$ Neurosci 2:170-176. 
Michenfelder JD, Theye RA (1968) Hypothermia: effect on canine brain and whole-body metabolism. Anesthesiology 29:1107-1112.

Neal MJ, Massey SC (1980) The release of acetylcholine and amino acids from the rabbit retina in vivo. In: Neurochemistry of the retina (Bazan NS, Lolley RN, eds), pp 191-208. Oxford: Pergamon.

Niemeyer $G$ (1975) The function of the retina in the perfused eye. Doc Ophthalmol 39:53-116.

Noell WK (1958) Studies on visual cell viability and differentiation. Ann NY Acad Sci 74:337-361.

Norberg K, Siesjo BK (1976) Oxidative metabolism of the cerebral cortex of the rat in severe insulin-induced hypoglycemia. J Neurochem 26:345-352.

Parks JM, Ames A III, Nesbett FB (1976) Protein synthesis in central nervous tissue: studies on retina in vitro. J Neurochem 27:987-997.

Paul RJ, Hardin DC, Raeymaekers L, Wuytack F, Casteels R (1989) Preferential support of $\mathrm{Ca}^{2+}$ uptake in smooth muscle plasma membrane vesicles by an endogenous glycolytic cascade. FASEB J 3:22982301.

Pournaras CJ, Riva CE, Tsacopoulos M, Strommer K (1989) Diffusion of $\mathrm{O}_{2}$ in the retina of anesthetized miniature pigs in normoxia and hyperoxia. Exp Eye Res 49:347-360.

Sickel W (1972) Retinal metabolism in dark and light. In: Handbook of sensory physiology, Vol 2, Physiology of photoreceptor organs (Fuortes MGF, ed), pp 667-727. Berlin: Springer.
Somlyo AP, Walz B (1985) Elemental distribution in Rana pipiens retinal rods: quantitative electron probe analysis. J Physiol (Lond) 358:183-195.

Steinberg RH (1969) Comparison of the intraretinal b-wave and d.c. component in the area centralis of cat retina. Vision Res 9:317-331.

Steinberg RH (1987) Monitoring communications between photoreceptors and pigment epithelial cells: effects of "mild" systemic hypoxia. Friedenwald lecture. Invest Ophthalmol Vis Sci 28:1888-1904.

Tornquist P, Alm A (1979) Retinal and choroidal contribution to retinal metabolism in vivo. A study in pigs. Acta Physiol Scand 106: 351-357.

Walseth TF, Graeff G, Krick TP, Goldberg ND (1981) The fate of ${ }^{18} \mathrm{O}$ in guanosine monophosphate during enzymic transformations leading to guanosine $3^{\prime}, 5^{\prime}$-monophosphate generation. J Biol Chem 256:21762179.

Winkler BS (1981) Glycolytic and oxidative metabolism in relation to retinal function. J Gen Physiol 77:667-692.

Winkler BS (1989) Retinal aerobic glycolysis revisited. Invest Ophthalmol Vis Sci 30:1023.

Young RSK, Olenginski TP, Yagel SK, Towfighi J (1983) The effect of graded hypothermia on hypoxic-ischemic brain damage: a neuropathologic study in the neonatal rat. Stroke 14:929-934.

Zuckerman R, Weiter JJ (1980) Oxygen transport in the bullfrog retina. Exp Eye Res 30:117-127. 